\title{
An economy and ecosystem symbiosis: barrier systems for water conservation and pollution control
}

\author{
KR Legge Department of Water and Sanitation, South Africa
}

\begin{abstract}
An awareness of the rate at which water resource development took place in South Africa being supply driven, until relatively recent times, leads to an appreciation of the changing philosophy in respect of water conservation and pollution control, as well as essential amendment to principles and procedures. Reconciling water demand and supply in catchments requires concurrent consideration of available water quantity and quality. This stimulates the need for change in the way we view water uses and brings about business opportunities in the sector. The review of infrastructure designs in support of water use and mining applications for industrial and mining waste has developed and transformed along with improved technology and changes in legislation since 1994 in South Africa. A containment barrier system comprises of both filter protected drains and low permeability liners which are visible in the short term until covered. They are required to perform effectively after initial use and are often inaccessible for the operating period and subsequent service life of decades or even centuries. This paper presents a regulator's perspective of commonly repeated deviation from accepted norms and standards in the engineering profession, as applied to pollution control facilities. Emphasis is placed on the standards of today with experience reflecting on the past five years of design reviews, leading to conclusions and recommendations for facility owners and practitioners. Examples of procedure, mechanisms, performance, specifications and socio-economic benefits are addressed. It is postulated that in the near future many mining and industrial developers will choose to improve containment standards of barrier systems as a component of reengineering water demands and for economic advantage while embracing contributions from ecosystem services.
\end{abstract}

Keywords: water conservation, pollution control, barrier systems, ecosystem services

\section{Introduction}

The development of water resources infrastructure reflects an increasing rate in consumptive use with time, and that only in recent decades has appreciation of water conservation with demand management and resource quality grown significantly. The process and practice followed in pursuit of authorisation for waste management facilities has evolved significantly over the past three decades with changes in philosophy, technology and performance standards. The need for and process of change with time is reported along with some of the experiences to which the South African regulator has been exposed. The intent is to provide an understanding of the review process with its responsibilities and limitations while simultaneously highlighting elements of the practice which are detrimental to the resource requiring protection, to facility developers or owners, and to design and construction practitioners.

The range of experiences and case studies reported on addresses the phases through which performance standards changed. It is not intended to be an all embracing report on state-of-the-art technology, but it is intended to report on the reasons for accepting or rejecting proposed designs and constructed works for the future benefit of the industry which seeks compliance with performance standards in a cost-effective manner. Reconciling water availability and increasing demand in the near future requires today's decisions to make provision for sustained mining practices in several regions. 


\section{Changes in philosophy over time}

A brief overview of water resources development legislation and commensurate regulatory structures and objectives gives significant insight into the rate of change of development with time, with associated generation of waste or pollution and significance attributed thereto.

\subsection{The 1800s}

Taking ourselves back in time to the 1800s we would have known of the history that had brought us to that time - a fairly sparsely populated country which had seen several colonial powers and regional wars come and go. The Portuguese, the Dutch and the British, amongst others, had visited the country. The first dam was constructed in 1800 as an earth embankment structure situated in the Northern Cape. In 1860 two further similar dams were constructed in the Eastern Cape and Gauteng provinces. By the turn of the century a total of 30 dams had been constructed, the highest of which was an $18 \mathrm{~m}$ earth embankment although the first masonry and gravity structures had come into being. Most developments were for agricultural water supply with only eight dams being for municipal water use. In the late 1800s, the former provinces of Natal and the Cape were under British rule, while the Transvaal and Orange Free State were Boer Republics.

The establishment of a hydraulics division in 1875 under the Commissioner of Public Works in the Cape Colony marked the birth of a very important Department of State. This department's work varied widely and was of the highest technical order, which was indispensable to the development of all sectors of the economy at that time. The first hydraulic engineer was John G Gamble who was an extremely competent engineer. The son of the famous Andrew Geddes Bain, known as Thomas Charles John Bain followed him in 1885.

In 1903, following the changes brought about by the two South African wars, arrangements were made to second two irrigation engineers (Messrs Kanthack and Hurley) from the Indian Irrigation Service to each of the colonies of the Cape and the Transvaal. These two engineers played a major role in moulding the early water policies and development in South Africa.

During the period 1902 up to the Union in 1910, water matters were dealt with in the four colonies; Cape, Transvaal, Natal and the Orange Free State, as follows:

- In the Cape, the Irrigation Department was mainly a technical department attached to the Public Works Department with FE Kanthack as the director, which had only scanty funds and a small staff component to undertake responsibilities. It was, however, due to the Cape Irrigation Act of 1906 (Juta 1907) that some extraordinary progress was made by a policy of assisting irrigation development through irrigation boards which included irrigation farmers who were required to allocate and distribute water in their districts. However, the lack of staff and funds severely hampered the essential task of collecting hydrographic data and systematically surveying the colony.

- In the Transvaal, the chief engineer FA Hurley headed the Irrigation Department which fell under the administration and control of the Secretary for Lands. The Transvaal concentrated on investigation of major projects, most of which proved to be too expensive to implement.

- In the Orange Free State, irrigation matters were dealt with by the director of public works.

- In Natal, irrigation matters fell under the Surveyor General and for all practical purposes, no irrigation work was undertaken.

The Union Irrigation Department formally came into being by the establishment of a new Act, Act no. 8 of 1912, known as the Irrigation and Conservation of Water Act (Union of South Africa 1940). The objectives of this Act were to consolidate and amend the laws enforced in the Union relating to the use of water in public streams for domestic, irrigation and industrial use and to provide facilities/infrastructure for the irrigation of land and use of water. This Act was destined to encourage the construction of storage works 
where the river flow during the low flow season was insufficient for direct irrigation by extracting water from runoff river diversion works.

At Union, considerable reorganisation and rationalisation took place. The way forward then took the form of active involvement of groups of irrigators with a policy of systematic research and investigation taken from the Transvaal model. Thus, Kanthack became the first director of irrigation and FA Hurley the assistant director under the union. The organisation was established to administer and implement the provisions of the Act, focusing on decentralisation. Decentralisation took the form of a circle engineer who was responsible for everything within his circle. Head office essentially controlled and reviewed the activities that took place in the nine circles. The period 1912 to 1914 was largely taken up by reorganisation, establishing circle boundaries etc., and this period was immediately followed by the first World War which brought about new challenges as many staff members enlisted for service and the prolonged drought was broken by unprecedented rain in 1916.

So it was in the following years that dams like Hartbeespoort Dam, Lake Mentz, Tygerpoort, Kamanassie, Grassridge and Lake Arthur were built.

Cooperative governance was investigated as AD Lewis was called upon to investigate development of the lower Orange River that had formed the boundary between the South African Union and German South West Africa. Lewis left Cape Town on 20 November 1912 by horse and cart. Only two of the four horses drawing his cart made it to Pella on the 27 November due to the tough going. Thereafter, he left the horses and cart behind and made his way by foot carrying all necessities with him. Two weeks later he had covered the $400 \mathrm{~km}$ down river to the Orange River mouth, making notes of every physical feature and irrigation potential. By 30 December 1912, Lewis had completed a report on the irrigation potential of the lower Orange River.

The onset of the depression brought about actions to relieve unemployment in various districts, and projects such as the Pongola Irrigation Scheme were started in 1932. Due to the increase in hardships for the unemployed and the consequences of the drought, the Department of Labour requested that the Department of Irrigation fast track further schemes and the Vaal-Harts and the Loskop irrigation schemes were started.

Further changes were brought about with the Vaal River Development Act, Act 38 of 1934 (Union of South Africa 1934) which had the notable feature of the tendency towards state ownership of water.

At the end of the 1930s, the department had a large staff component and many resources associated with the rapid growth in construction. The outbreak of the Second World War brought about changes yet again with the director of the Department of Irrigation being seconded to the Technical Committee of Defence on War Supplies, while a large number of officers took military rank in the Works Directorate, and many other staff members became the core of four companies for the Mobile Field Force. Over $50 \%$ of the department's technical staff was released for military service.

The year 1945 brought a radical change in thinking on water management. During the past half century, the department's emphasis had been on supplying water to irrigators who had used much of the water rather extravagantly. The ever-growing needs of expanding mines and industry, as well as domestic use and the acceptance of the fact that the water resources were limited, required a complete change in water legislation. Thus the functions of the department were expected to change. As a first step, pro rata tariffs for irrigators were introduced as far as possible, rather than the flat rate based on land schedules. The Minister was also empowered to grant subsidies to municipalities for the construction of municipal water supply schemes. The next step towards meeting the growing demands was to establish separate planning and research divisions in 1949.

On 7 April 1950, the Governor General appointed a water law inquiry commission to investigate and report on matters related to the existing laws and their required amendments in order to provide for the utilisation of water resources, to the best advantage to the people. The result was that parliament in 1956 passed an Act that repealed the 1912 Act and heralded a new era in water resources in South Africa. The 
new Water Act, Act 54 of 1956 (Union of South Africa 1956) specifically provided that there shall be no private ownership of public water, i.e. in a natural stream of water whether visible or not which flows over two or more original properties in a defined channel and which is capable of common use. This Act also placed water use for agriculture, industry and urban demands more or less on an equal footing. Riparian rights were retained where the state did not control the water, to the extent that riparian owners were entitled to a fair share of the normal flow of a public stream. This Act also gave the Minister absolute control over water in dolomitic areas and subterranean water controlled areas. The host of new responsibilities placed on the department lead to the establishment of additional divisions and sections such as the Division of Water Utilisation with its subdivisions of agricultural water and industrial water; the separation of the design and planning functions; the creation of a hydrological division, and the formation of a section to deal with the administration of permits for the abstraction of water etc.

In 1962, the Prime Minister announced in parliament the development of the Orange Fish River project. This yielded another change from the norm of planning, designing and constructing in-house by the introduction of the use of consulting engineers and contractors, for the design and construction of certain components of the work such as the main dam and tunnel. In 1966, the State President appointed a 15-member commission to investigate all matters pertaining to water and this commission found a need for investment in scientific research. The hydrological research centre at Roodeplaat Dam was approved in 1969-1970 and opened in 1972. A number of regional committees were also established to advise the Minister of Water Affairs on matters including interactions with neighbouring states.

The 1970s were characterised by multi-purpose dam development projects. By the 1980s, the storage infrastructure development rate had slowed and the department had been referred to by some members of cabinet as a junior department. In 1992 an interim government came into being as preparation for the first democratic election of the country in which all South Africans of age participated. This brought about a process of development of principles for water resources management and a new legislation - the National Water Act, Act 36 of 1998 (Republic of South Africa 1998b). The primary objectives of which are: sustainable water resources management and poverty alleviation.

\subsection{The democratic era inheritance and changes}

Today South Africa is a relatively young developing country in which the industry matured following a foundation in both agricultural expansion and mining practices in the hinterland. A century ago the results of early mining raised very limited concerns with respect to pollution as seen Table 1 , and legislation was introduced in 1935 to assist with the management of water resources in the upper Vaal River catchment, which is one of the major rivers of the country and situated to the south of the gold mining reserves. Cities such as Johannesburg developed around these mining practices. For many years, pollution due to other sources such as municipal solid waste was not considered to be a serious threat to the water resources nor environment.

As recently as the 1970s a senior official within the regulatory system had stated publicly that landfill waste was not considered a source of pollution to be of concern. The practices for land filling were thus unregulated and municipal solid waste was disposed of in unlined abandoned quarries, random valley fills, and in any other suitable or accessible positions including as fill material to reclaim wetlands.

It was during the 1980s that an academic institution established a research program to look into whether landfills were indeed a source of pollution or not. This program looked at two existing facilities which had been operating for many decades, the one facility known as Waterval was a site serving the early gold mining city of Johannesburg. The other waste facility was situated at the other end of the country, just outside the city of Cape Town and known as Coastal Park. The investigation into these waste bodies included aspects of conventional geotechnical engineering such as drilling auger holes through the waste body and profiling the holes with depth, keeping a record of moisture content, extent of waste degradation, type of waste, extent of ash, and layering, along with the presence of free liquid. This investigation concluded that landfill is indeed a source of pollution and that the main drivers of leachate 
development were related to drainage of surface and surrounding water; the moisture of the waste being deposited including whether co-disposal was taking the place of liquids with solids; and the climatic water balance at the site. The research process had also included monitoring of groundwater with distance from the waste facility and it was noted that in the case of Coastal Park landfill, a pollution plume was moving off site at about $4 \mathrm{~m} /$ annum.

Table 1 Publications showing awareness of mining-related pollution over the past decades (Liefferink 2012)

\begin{tabular}{|c|c|}
\hline 1960 & Final Report Interdepartmental Committee on Dolomitic Mine Water: Far West Rand, DWAF \\
\hline 1963 & $\begin{array}{l}\text { Council for Scientific and Industrial Research (CSIR) "Commentary on the Final Report of the Interim } \\
\text { Departmental Committee on Dolomitic Mine Water: Far West Rand" 28/02/1963/10/02/1964 }\end{array}$ \\
\hline 1995 & $\begin{array}{l}\text { Screening Surveys of Radioactivity in the Mooi River Catchment by the Institute of Water Quality Studies } \\
\text { of the DWAF }\end{array}$ \\
\hline 1996 & $\begin{array}{l}\text { Scientists predict West Rand Decant in } 2002 \text { and suggested a solution in "An Integrated Strategic Water } \\
\text { Management Plan for the Gauteng Gold Mines". The success of the proposed solution is dependent on } \\
\text { the mines, water suppliers, water users and Government adopting an Integrated approach - with } \\
\text { Government taking the lead role. The Western Utility Corporation developed an alleged technical and } \\
\text { economical viable solution but at the time of writing, Government has not given approval to their initiative, } \\
\text { Government alleges that the polluter cannot be allowed to profit from the pollution. }\end{array}$ \\
\hline 1999 & $\begin{array}{l}\text { Report, "Radioactivity Monitoring Programme in the Mooi River (Wonderfonteinspruit) Catchment". } \\
\text { Institute for Water Quality Studies, DWAF, April. Mining activities are a major contributor to uranium and } \\
\text { uranium series radionuclides within the catchment. Concentrations decrease downstream of the sources, } \\
\text { indicating removal from the dissolved fraction by interaction with sediments. }\end{array}$ \\
\hline 2002 & $\begin{array}{l}\text { Publication of the "Radioactivity study as sediments in a dam on the Wonderfonteinspruit Catchment". } \\
\text { Conducted by the Council for Geoscience and commissioned by DWAF (Wade et. al.) } 2002 \text { (WRC) }\end{array}$ \\
\hline 2002 & $\begin{array}{l}\text { Publication of the "Tier } 1 \text { Risk Assessment of selected Radionuclides in sediments of the "Mooi River } \\
\text { Catchment". WRC Report 1095/1/02 by P. Wade. Radionuclides are concentrated by sediments } \\
\text { downstream of their source. Sequential extractions show that these Radionuclides are distributed in } \\
\text { multiple phases within the sediments and that they may be remobilised by environmentally by plausible } \\
\text { chemical processes such as AMD. }\end{array}$ \\
\hline 2002 & $\begin{array}{l}\text { Coetzee et. al. of the Council of Geoscience reported on "Uranium and heavy metals in sediments in a } \\
\text { dam on the farm Blauwbank." The study confirmed the findings of Wade et. al. and used further } \\
\text { sequential extractions to characterise the sediments in a dam downstream of mining activities in the } \\
\text { Carltonville area. }\end{array}$ \\
\hline 2005 & $\begin{array}{l}\text { Publication, WRC on "Impacts of gold mining activities on water availability and quality in the } \\
\text { Wonderfonteinspruit River Catchment". Mining related impacts such as large scale land degradation } \\
\text { associated with dewatering of domestic aquifers and widespread pollution of surface water and } \\
\text { groundwater systems are discussed. }\end{array}$ \\
\hline 2005 & $\begin{array}{l}\text { Publication, Council for Geoscience, "Catchment contamination of wetlands by the Witwatersrand gold } \\
\text { mines processes and the economic potential of gold in wetlands" by H Coetzee et. al, Report number } \\
\text { 2005- } 0106 \text {. For more than a century the mines of the Witwatersrand have discharged contaminated } \\
\text { water into the streams and rivers of the area, which led to a formation of a system of large wetlands. } \\
\text { Concerns have been raised about their ability to cope with the pollutant loads flowing into wetlands. }\end{array}$ \\
\hline 2006 & $\begin{array}{l}\text { Publication of "An Assessment of Sources, Pathways, Mechanisms and Risks of current and potential } \\
\text { future pollution of water and sediments in gold mining areas of the "Wonderfonteinspruit Catchment". } \\
\text { Report WRC, H Coetzee et. al. Council for Geoscience, 2004, Report number 1214/1/06 }\end{array}$ \\
\hline
\end{tabular}

DWAF - Department of Water Affairs and Forestry; AMD - acid mine drainage; WRC - Water Research Commission. 


\subsubsection{Development of initial waste management philosophy}

This research led to the belief or philosophy that it was only necessary to contain the most hazardous of waste material, whereas for small sites or low risk point sources of pollution the groundwater regime could employ the philosophy of attenuation for protection. During the early 1990s the regulatory body responsible for water resource protection developed a suite of guidelines which became the accepted standard against which the permitting of landfills took place. These standards were based on the philosophy that mitigation can be achieved by containment for the most severe pollution source and attenuation for the low significance pollution sources, with a range of standards between these two extremes as shown in Figure 1(a). Classification of waste was thus addressed by toxicity and concentration, leading to classification of waste as either hazardous or general. The size of a site was taken into consideration based on the rate of waste disposal leading to a second parameter of large, medium, small or communal facilities. To give effect to the research result which identified available water as a critical factor, it was accepted that a third factor would be water balance at the particular site, with the leachate producing facilities conceptualised as being those situated at positions where, for the wettest six months of a year, the rainfall would exceed evaporation as shown in Figure 1(b). Sites are thus classified with a third parameter as either water surplus or water deficit.
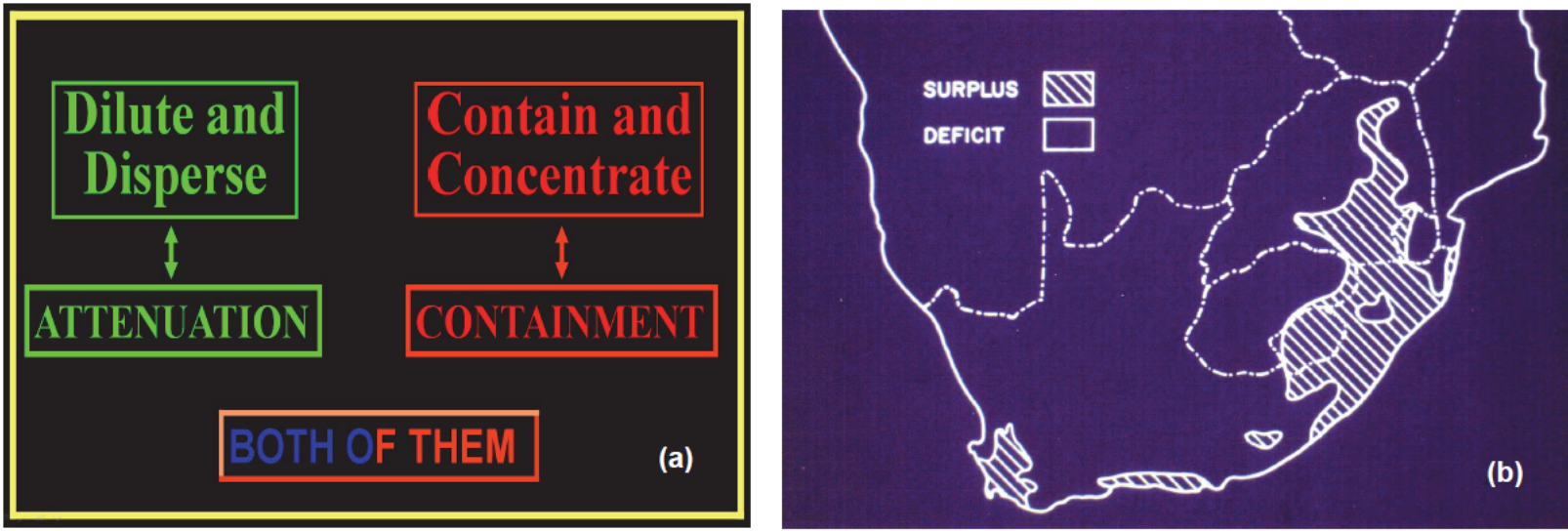

Figure 1 The 1990s' philosophy on pollution generation and range of mitigation (Ball 2002): (a) The extreme philosophies of dilution and dispersion relying on attenuation through a range of standards to containment; (b) The concept of water balance showing water surplus and water deficit areas based on precipitation and evaporation only

The classification of sites as hazardous or general; large medium or small; and water surplus or water deficit then led designers to minimum requirements for containment barriers beneath such facilities. It is recognised that these containment barriers did not pursue containment to the extent that was reasonably achievable, but allowed for some dilution and dispersion. Thus only hazardous waste facilities in recent years generally employed a double liner system of which at least the primary liner was a composite liner made up of both a geomembrane and a compacted clay liner, and this compacted clay liner being made up of multiple layers with a total thickness of at least $600 \mathrm{~mm}$. In all cases where double liners were specified as a minimum requirement, they were separated by a leak detection system. So too was it a minimum requirement for all containment barrier systems incorporating a geomembrane that there shall be a protection layer between geomembrane and the overlaying leachate collection system. For the general waste facilities clay only barriers were employed with thickness in proportion to size classification, and leachate collection systems required only for those sites situated in a positive water balance area.

This range of documents gave waste facility owners guidance beyond design and construction, and included operation and monitoring of performance. The minimum requirements were used extensively at a time when the country was going through significant change in legislation and a growing environmental awareness with recognition of the limits to natural resources. Thus while these documents were employed for over a decade leading into significant law reform, the regulators and professional societies involved in 
waste management used the opportunity to ascertain the suitability of the philosophy and the requirements.

There were several lessons to be learnt from applying these requirements or standards in the local framework. It was recognised early on in their application that even in the driest of regions, falling well within the water deficit classification, leachate was indeed produced within the waste body and was as a result a source of pollution as seen in Figure 2(a). Similarly, it became quite apparent that the waste stream to landfall varied with time and position, and this had an influence on the performance of leachate collection systems in the water surplus areas. These leachate collection systems were found to block readily as seen in Figure 2(b), as they were not protected by filter systems defined within the standards and thus not employed by the owner or designer. So too was significant experience gained in the use of geomembranes as liner materials.
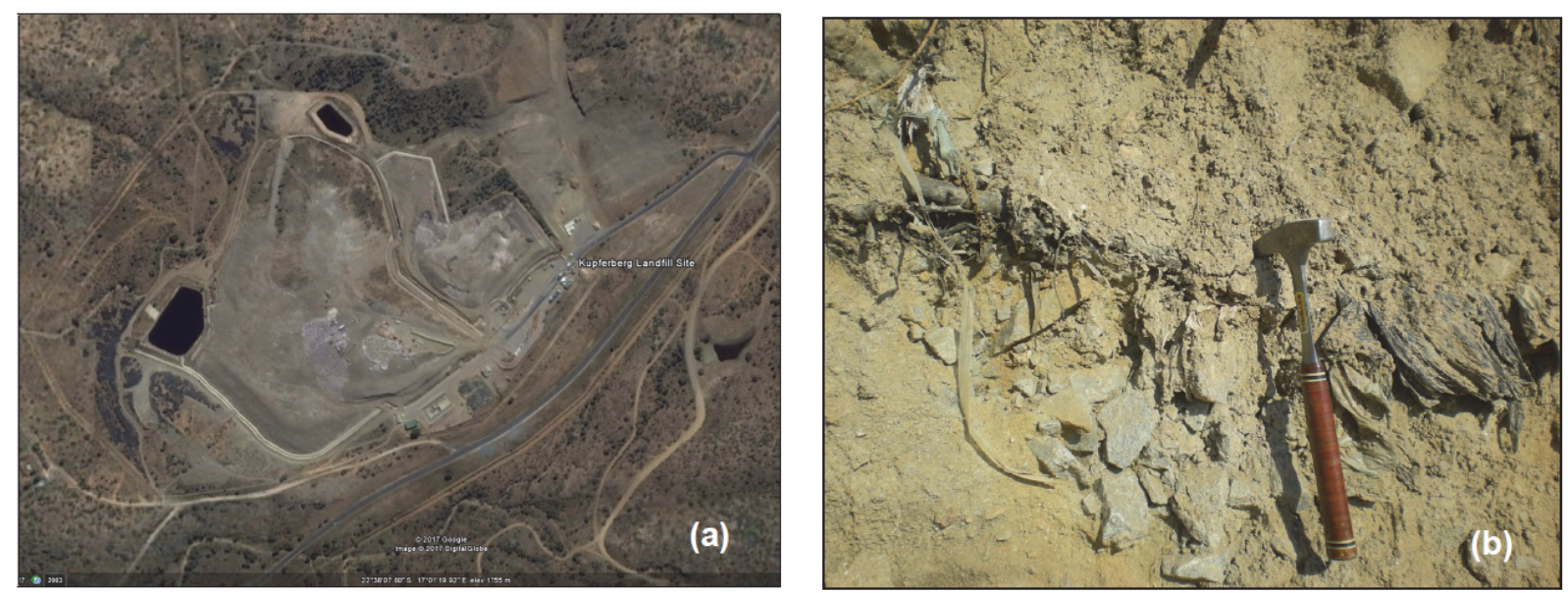

Figure 2 Experiences from applying the Minimum Requirements for Waste Disposal (DWAF 1998) philosophy: (a) Excessive leachate is generated even in a desert environment (Google Earth image of Kupferberg, Namibia (Alphabet Inc. 2019)); (b) Aggregate leachate collection systems clog readily if not protected by a filter (Shamrock \& Msiza 2015)

The use of geomembranes in South Africa had historically been for applications where water containment was required, often associated with inter basin transfers, or delivery of raw water over significant distance from its source and hence competent storage was required for this valuable asset.

\subsubsection{Development of modern philosophy}

The new-found international relations with the world allowed South Africa to exchange technology with countries willing to do so, and the advent of the Internet facilitated an even greater rate of sharing of knowledge and experience.

The new legal framework placing environmental protection and human rights high on the legislative agenda. The Constitution of the Republic of South Africa, 1992 and 1996, Bill of Human Rights demanded a rethink of waste management and pollution control measures. A hierarchy of waste management strategies emerged with a priority to address the rapidly deteriorating limited water resources as seen in Figure 3. It is widely known that with the long history of mining practices in certain parts of the country, that salts are a significant problem in the groundwater and river systems (Brink et al. 2009). The assimilative capacity of many watercourses and rivers was exceeded bringing about the de-oxygenation and anaerobic conditions with associated loss of biota. Many human lives and the health of communities or persons who made use of runoff river water supplies were placed at risk. 

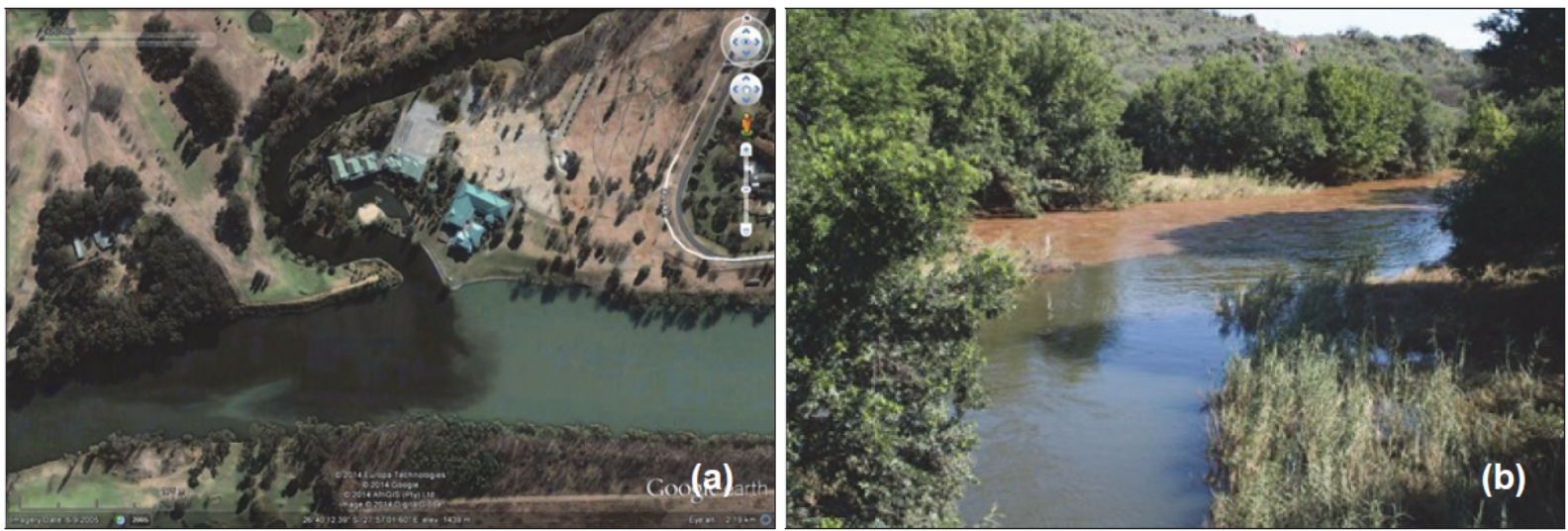

Figure 3 Visual evidence of waste and mining pollution in rivers: (a) The confluence of the Vaal and Klip Rivers (Google Earth Image of confluence the Vaal and Klip River); (b) The confluence of the Steelpoort and Klip River (photo courtesy RB Martin)

This attention to the significance of South Africa's water resources was escalated largely by the World Commission on Dams South African Initiative, which recognised the scarcity of water in this region of the world. Similarly, the dependence of poor persons on natural resources drew attention to the water quality of river systems which was further emphasised by acceptance of international treaties and the importance of biodiversity and wetlands in the remediation of water resources impacts.

Despite the privilege of a domestic geomembrane manufacturer and several lining installation contractors, as well as local geotextile manufacturer with several suppliers, the investigations and performance assessment of geosynthetic products was undertaken by academic institutions to a large extent, and to a lesser extent by the regulator itself. With the limited resources available for research, the use of international literature, access to material producers from around the world, and cooperative studies were pursued.

\subsubsection{Monitoring of Minimum Requirements based facilities}

A further consideration of these shortcomings of the Minimum Requirements was realised as the regulator pursued monitoring of existing facilities and, in particular, those facilities incorporating a geomembrane liner. The requirement that hazardous waste facilities and large leachate producing facilities monitor the performance of the primary liner through the use of a leak detection system was fatally flawed due to the prescriptive means. This leak detection system is given effect by a secondary liner which in all cases except for the hazardous waste lagoon, is a compacted clay liner only, and typically of the same material as within the primary liner but even thinner (usually only two layers). It was thus clear that the apparent reporting of suitable containment by the primary liner systems was in fact not a true reflection of the primary liner performance, but rather a failure of the secondary liner to report leakage exceeding the expected threshold. This was deemed a fatal flaw of the Minimum Requirements, and in particular for the most important waste streams being those which receive the toxic and larger volumes of waste.

Although the Minimum Requirements 1998 applied to waste management, the mining regulations under the National Water Act came into being in 1999 with greater emphasis on enforcement in 2006. The monitoring of drainage systems to three coal residue deposit facilities in Mpumalanga during the period 2007 to 2011 gave greater insight into liner performance. Although sites 1 and 2 were adjacent to each other and Site 3 some $50 \mathrm{~km}$ away, the drainage systems of finger and toe drains above the Site 1 compacted clay only liner compared to the composite $1.5 \mathrm{~mm}$ thick linear low-density polyethylene (LLDPE) geomembrane and $450 \mathrm{~mm}$ thick compacted clay liner $(\mathrm{CCL})$ of Site 2 showed the latter reported approximately $118 \%$ more leachate per month in drain flows on average (over different lengths of monitoring periods). A comparison between Site 1 and the distant Site 3 of similar composite liner showed a higher drain flow of the order of $400 \%$. However, by comparing the 2011 season results only, so as to 
remove climate and rainfall as a variable, the drainage flow increased by about $270 \%$ above a composite liner compared to a clay only liner. (Acknowledgement to Jones and Wagener Consulting Engineers). Drain flow should not be confused with seepage losses through liners. The difference in the volume of retained polluted water is emphasised for appreciating water conservation as well as pollution control.

\subsection{Importation of technology and renewable water}

Regulations employed in foreign countries were considered for their suitability to the South African landscape. In particular, the countries of Australia, Canada, Germany, and the USA, along with the supporting technology, were studied.

An analysis of international standards led the regulator to believe that South Africa had one of the lowest standards of containment for waste amongst those countries in the world, which did regulate waste containment barriers systems at that time. The worldwide survey (Koerner \& Koerner 2007) confirmed that the world standard for waste containment, irrespective of whether the waste was hazardous or general, was the employment of a composite (geomembrane plus compacted clay in intimate contact) liner within a barrier system, whereas South Africa was to a large extent relying on clay only liners for partial containment and in many cases relying on rudimentary drainage layers and clay only liners for controlling the rate at which pollution took place.

Although it was tempting to adopt a standard from another country which had experience in modern containment standards for barriers systems, the South African situation of a large industrial and developed economy in a water scarce environment had to be taken into consideration. The water availability per capita per annum (Table 2) needed consideration to reflect the acceptable assimilative capacity of our ecosystems within watercourses.

Table 2 Estimated renewable water available in cubic meters per person per annum for selected country/region as at 1995, extracted from global image (World Resources Institute 2003)

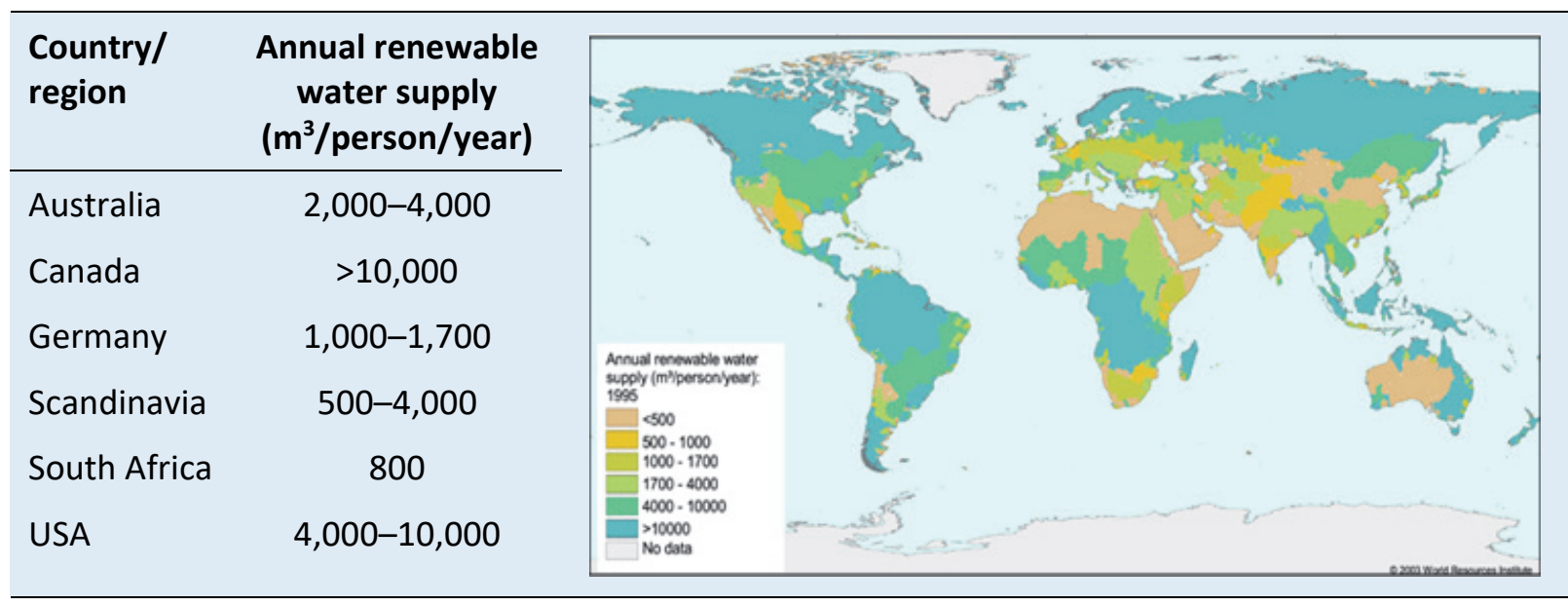

The small volume of water available per person per annum in South Africa reflects the importance of maintaining aquatic ecosystems in a healthy functioning condition. It became quite apparent that the historic philosophy of the past 20 years which allowed for dilution and dispersion relying on attenuation was not acceptable.

This situation was further aggravated by the limited water quantity for dilution and realisation that future large dam developments for water supply to agriculture, mining and industry are exceedingly expensive, as reflected in the change to rate of development shown in Figure 4. 
Development of Dams in South Africa (1800 - 2018)

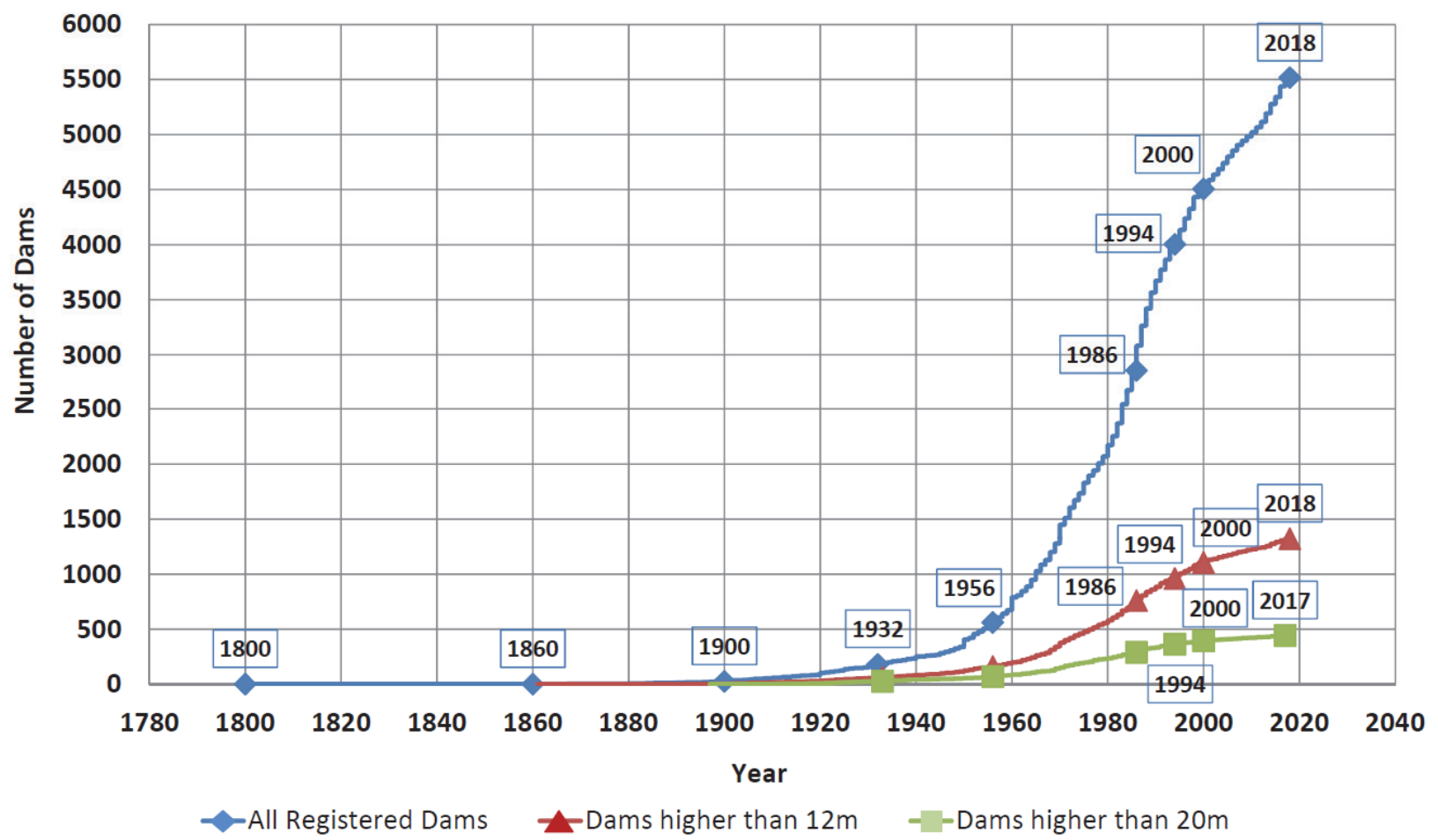

Figure 4 The development of dams in South Africa over time

\section{Ecosystem services and catchments}

\subsection{Invasive alien plant impacts on water assurance}

The invasive alien plants (IAPS) have been introduced in South Africa over recent centuries either unintentionally or intentionally. Some species were introduced in fodder imported during the South African wars, whereas other species have been introduced for a variety of reasons ranging from aesthetics such as the well-known Jacaranda trees that line the streets in the city of Pretoria or for the production of paper or provision of mining props. It is only in recent decades that the conservation of land has given attention to restricting or removing such species, with commensurate studies into the extent to which these species consume the water resources.

Forestry has been an important sector of industry in South Africa, but afforestation places a significant demand on water resources. It is estimated that commercial forestry covers about 1.5 million ha (57\% pine, $35 \%$ eucalypts and $8 \%$ wattle) which equates to about $1.2 \%$ of the area of South Africa. However, the regions used for afforestation receive higher rainfall and yield a disproportionately large share of the streamflow, particularly the low flow or base flow of streams. Scott et al. (1998) produced an easy to use GIS based model to provide data on the effects of forestation on stream flow reduction and particularly base flow. The empirical model estimates the effect of afforestation to be a $3.2 \%$ reduction $\left(1,417 \times 10^{6} \mathrm{~m}^{3}\right)$ and low flows by $7.8 \%\left(101 \times 10^{6} \mathrm{~m}^{3}\right)$ per annum, however, the greatest effects are reported in Mpumalanga and Limpopo provinces. Subsequently, several methods have been developed to estimate water consumption by forestry, however, Mallory et al. (2011) caution against overestimating the increase in yield achieved by removing IAPs and suggest model results are tested against the hydrological principle that removal of IAPs cannot put back more water than that which occurs naturally in a stream. Some hydrological models failed this simple test, due to their use being out of context. The 1998 estimates of water consumption have been revised by Le Maitre et al. (2016) downward to $2.9 \%$ following recent research improving the estimates of plant water use and improved flow reduction models. 
Over the past century several species of the Prosopis genus have been introduced into South Africa, many of which have become invasive. The Prosopis genus is a collection of about 45 flowering species of spiny trees and shrubs which are legumes. A study in the Northern Cape region of South Africa into the effects of clearing and the seasonal dynamics of groundwater use by these species showed that clearing the invasive Prosopis trees reduced groundwater consumption by $70 \mathrm{~m}^{3} / \mathrm{month} /$ ha during spring (Dzikiti et al. 2013). A similar preceding study in the Kenhardt region revealed a groundwater saving of $50 \mathrm{~m}^{3} / \mathrm{ha} / \mathrm{month}$ for the same species (Fourie et al. 2002).

The Working for Water program has provided significant socio-economic benefits, including job opportunities and poverty alleviation over and above reductions in water losses to IAPs and land-care through fuel mass reduction in the event of veld and forest wild fires. The value of maintaining invasive alien eradication programmes is emphasised by Preston et al. (2018) who studied the recently constructed Berg River Dam (2006) and De Hoop Dam (2013) catchments and reported an anticipated 51\% and 44\% reduction in yield respectively, should IAPs be left to invade the catchments over the economic life of the dam.

\subsection{Erosion, sedimentation and dams}

The development of water storage facilities over the past century has led to an increasing awareness of soil erosion within catchments and the resultant sedimentation of dams. Reservoir sedimentation leads to a loss of storage capacity, damage to mechanical items, and upstream and downstream impacts.

Of the approximately $7,000 \mathrm{~km}^{3}$ of storage of dams worldwide, approximately $3,000 \mathrm{~km}^{3}$ is for dead storage and the remaining $4,000 \mathrm{~km}^{3}$ is for live storage of which the majority $\left(3,000 \mathrm{~km}^{3}\right)$ is for hydropower, and the remainder $\left(1,000 \mathrm{~km}^{3}\right)$ is for irrigation, potable water, mining and industry (Msadala \& Basson 2009). In South Africa the mean annual runoff is estimated at $49 \mathrm{~km}^{3}$ and total storage in large dams is estimated at $33 \mathrm{~km}^{3}$. The rate at which storage capacity in dams is lost to sedimentation was based on hydrographic surveys of selected reservoirs from time to time. An analysis of the reservoir sediment deposit data showed that almost $25 \%$ of the total number of reservoirs have lost between 10 and $30 \%$ of their original storage capacity (Msadala \& Basson 2009). That study has shown that the average loss due to sedimentation in South African reservoirs is $0.3 \%$ per year whereas the rate for all the reservoirs in the world is rated at $0.8 \%$ per annum, but this varies widely.

The case study of the Mapochs Dam downstream of an opencast magnetite mine and on a tributary of the Steelpoort River is a case in point presented in Figure 5. The $25 \mathrm{~m}$ high dam constructed in 1974 receives runoff from the ever increasing opencast mine footprint and catchment which led to near total sedimentation by 2000 , with resultant loss of water supply to the nearby town of Roossenekal and to the mine itself. The owner pursued desilting in 2001, by means of hydraulic mining and recovery techniques, and deposition of the sediment in tailings storage facilities (TSF). Within ten years the dam had again lost almost all capacity due to sediment and investigations into options of reinstating water supply to users which included consideration of various methods of desilting, as well as raising of the dam wall itself. However, the most feasible option selection was a combination of mine rehabilitation and limited desilting by a repeat of hydraulic mining and placement downstream of the wall on new tailings facilities so as to make use of potential energy and reduce pumping costs. The cost of regenerating storage capacity within the dam was about twice the cost of that in a new storage facility, however, the water supply system and limited life of a new facility made it prohibitive. 

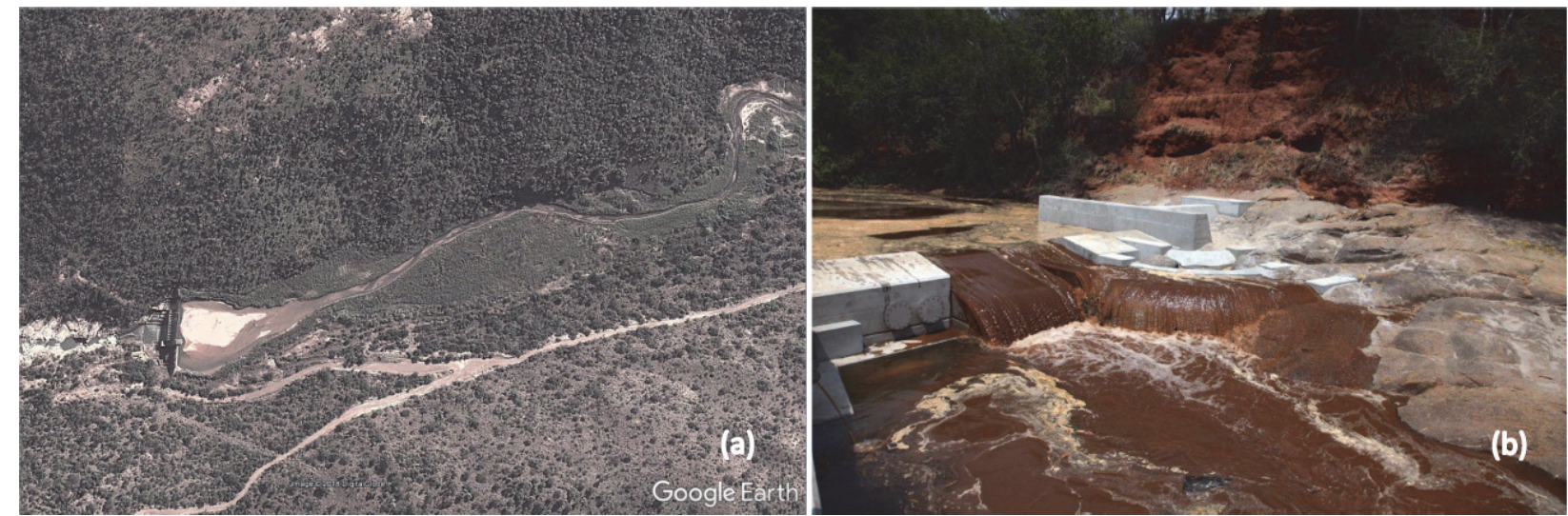

Figure 5 (a) Plan view of Mapochs dam showing extent of sediment fans at the inlet while sediment approaches the full supply level at the dam wall; (b) Image of the river downstream of Mapochs dam during overtopping events reflecting the elevated sediment load

The extent of sediment deposition in a reservoir, and in particular accumulation in the upper reaches, consequential increasing in flooding has been underestimated in the past (Rooseboom 2002). Rooseboom states that even with much improved modelling techniques available it is not possible to make exact long-term predictions, due to the complex nature of the processes involved. The consequences thereof, particularly with sediment accumulation above full supply level, include water trapped outside of the river system behind levees (Department of Water Affairs 2009 Welbedacht Report), and socio-economic impacts associated with land acquisition and relocation out of sediment and flood impacted areas many years after initial reservoir development.

\subsection{Reconciliation strategies}

The capacity of the country to meet its water requirements, now and into the future, can be found in a detailed report Integrated Water Resource Planning for South Africa - A Situation Analysis 2010 (Department of Water Affairs 2010b). It states water supply requires long-term planning, and strategies to source and supply water must be aligned to national development goals. Since publication of the National Water Resource Strategy in 2004, the Department of Water and Sanitation has undertaken strategic water resource assessments at water management area level, followed by supply and demand reconciliation studies for major river systems, metropolitan areas, growth centres, and smaller towns and villages across the country. This work is ongoing.

The adequate supply of water for many areas can be sustained only if immediate actions are taken to stave off imminent shortages. The foremost action is the concerted implementation of water conservation and demand management measures. Additionally, the re-use of water offers an immediate and practical supply for cities and fast-growing towns, desalination of seawater offers security to coastal centres, and opportunities for groundwater development must be taken up. The remaining opportunities to build more dams should always be considered in the light of alternative options to supply the necessary water.

A large proportion of the gold, platinum group metals and coal mining activities in South Africa are located in the Vaal River catchment, Crocodile West/Limpopo River catchment and Olifants River catchment, respectively. Water balance reconciliation strategies that seek to reconcile future water requirements with available resources over the next 20-30 years have recently been developed for the former two systems. These water reconciliation strategies address:

- Future water requirement scenarios.

- Water resources (sources of supply), taking account of the possible impact of climate change.

- Other interventions that could reduce demand or add water availability. 
- Ways of reconciling the requirements for water with the available resources.

- Monitoring and upgrading.

The challenge in reconciliation strategies is to ensure that the demand curve never exceeds the supply curve, illustrating available yield. A high growth trajectory is planned for as interventions can always be delayed in the event of lower growth, but it is often impossible to bring them forward to meet unexpected needs.

It is very clear from the reconciliation strategies that without active and immediate implementation of water conservation and demand management measures almost all water supply systems run into deficit before new resource projects, with their long lead times, can be implemented. "South Africa cannot afford to waste any water, anywhere, at any time" (DWA 2010).

The most important feature of water conservation and demand management is that it can be quickly and relatively cheaply implemented, with immediate results. Immediate savings of $10-15 \%$ can be targeted, with savings of more than $30 \%$ often achievable in the long-term. The reconciliation graphs accompanying all strategies show that supply targets will not be reached without serious measures and immediate investment in these measures.

Water re-use can also be implemented quickly. The purification and recycling of treated waste water and other effluent will be essential in cities and larger towns.

Groundwater is an under-used resource and its value often unrecognised, particularly in the case of smaller towns.

Desalination applies to the removal of salt from seawater, and is also a critical part of the treatment of acid mine drainage and other polluted and saline water inland. Desalination has been adopted as an emergency source for coastal towns in drought-stricken areas, is being considered as a source for coastal cities, and is being implemented for mine water treatment and urban supply on the Highveld.

The opportunity to build more dams is limited, with water delivered becoming increasingly expensive, especially given the long-distance transfers required. New dams must be weighed up in terms of impacts, economics and alternative options.

Catchment rehabilitation by way of IAP eradication may increase yield. The Vaal Dam is perhaps the best-known water storage facility in South Africa with a current full supply capacity (FSC) of 2,603 $\times 10^{6} \mathrm{~m}^{3}$. Following the 1956 raising the dam had a FSC of 2,330 $\times 10^{6} \mathrm{~m}^{3}$, with a yield when operated as a single unit of $1,029 \times 10^{6} \mathrm{~m}^{3} / \mathrm{a}$. The 1976 raising by mechanical gates increased the storage capacity by $300 \times 10^{6} \mathrm{~m}^{3}$, which increased the yield by $30 \times 10^{6} \mathrm{~m}^{3} /$ a (government gazette White Papers K-79 (Republic of South Africa 1979) and C-82 (Republic of South Africa 1982)). To put the water loss due to IAPs into perspective, the estimated water consumption per annum reported above approximates to the then yield of the Vaal Dam. It should be noted that invasive aliens are distributed widely and predominately in the Northern and Eastern regions of the country.

Water quality deterioration through pollution from agricultural, industrial and mining activities and, because of poor urban waste water management, is arguably the most serious threat to the country's water resources. Treatment and re-use of poor quality water offers an opportunity to solve a supply as well as a pollution problem.

The Department of Water and Sanitation has completed a report entitled "Assessment of the ultimate potential and future marginal cost of water resources in South Africa" (Basson et al. 2010). This report provides estimates of the ultimate availability of water, and a comparative costing of providing new supplies. Options range from the few remaining opportunities for large dams and transfers, the re-use of return flows, and the desalination of seawater. Meeting new demand from increasingly expensive new schemes may prove too costly to the country, requiring serious reassessment of how water is used by different sectors, what development is encouraged, and where growth nodes are planned. 
In many situations, the ecological reserve is not being met. So, for example, the Olifants River System is in balance if no further allowance is made for the reserve, but it is now estimated that the river needs in the order of 200 million $\mathrm{m}^{3} / a$ more water than it is currently getting if the reserves requirements are to be met. To address this, water would either have to be taken from existing users, or provided from newly developed resources, such as the De Hoop Dam. There are social, economic and ecological implications in this and implementing the reserve is going to be an increasingly difficult socio-economic balancing act.

Little additional water can be made available from conventional sources, and this water will be far more expensive. Challenges in meeting future requirements include:

- The need for equity and for improved services from limited resources.

- Growth in water requirements where supplies are not readily available.

- Deterioration in water quality (acid mine drainage, salinity and untreated waste water).

- The development of sources and resources without destroying the environment.

- The implementation of the reserve.

- Climate change.

Taking action in line with the reconciliation strategies put forward on the Department of Water and Sanitation website (Department of Water and Sanitation 2010b) will ensure that water is available for sustained growth and development for the foreseeable future.

For the mining sector to maintain current operations and develop further, it is necessary to recognise both the water quantity and quality required by a mine within a region. Future business planning thus requires water accounting by a mine to recognise the risk of potential water deficit (Figure 6), which can be mitigated to some extent by water conservation measures, including barriers to seepage losses and/or increasing water availability through invasive alien irradiation.

\section{Water Stress by Country: 2040}

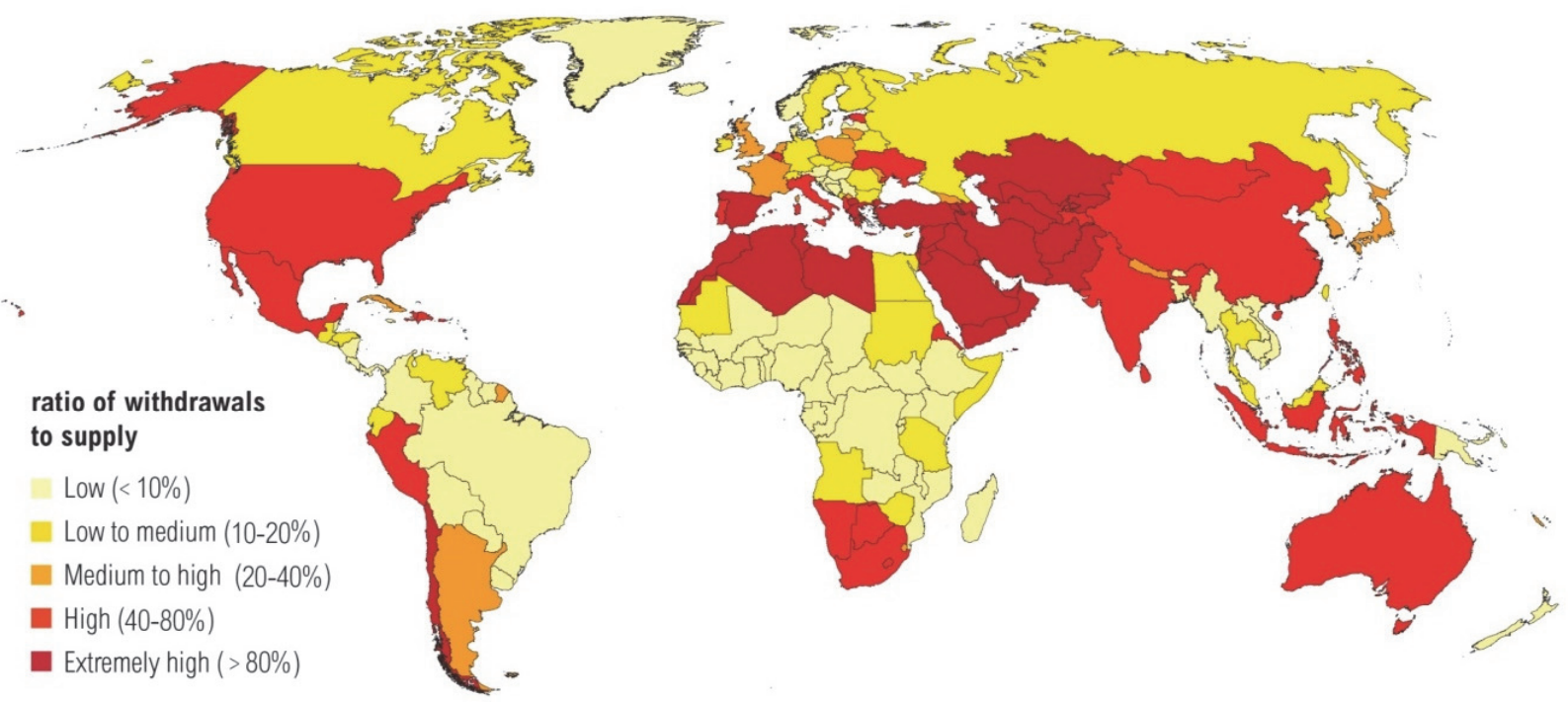

NOTE: Projections are based on a business-as-usual scenario using SSP2 and RCP8.5.

For more: ow.ly/RiWop

WORLD RESOURCES INSTITUTE

Figure 6 Water deficit regions for the world by 2040, as predicted by the World Resources Institute (2015) 


\section{Development of National Environmental Management: Waste Act: Regulations 2013, commencing in 2009}

While South Africa has a lean economy, it has an obligation to fulfil multiple responsibilities such as the alleviation of poverty; the provision of basic water of an acceptable quality to all its inhabitants; the right to a safe environment; and the protection of its environment for future generations. The prioritisation of needs and regulation required careful consideration so as to maintain a healthy economy and regulatory actions should be fair and just to participants within the social and economic framework.

It was thus decided to embark upon a consultative procedure with proposals to refine the historic Minimum Requirements leading to national norms and standards for the classification and containment of waste (following a revised waste assessment process) within the waste management hierarchy, which prioritised waste reduction and re-use only then followed with disposal to a facility designed for containment. This strategy would clearly lead to a change in waste stream and a change in resultant behaviour of the waste body. The intention was to move away from numerous small sites and move towards regionalisation of municipal solid waste facilities. An example of the change in waste stream was the regulators introduction of paying for plastic bags, so readily used in South African society at that time. This change brought about a reduction in the plastics content of new municipal solid waste streams, which changed strength characteristics and resultant angle of repose of waste and hence the outer slopes.

\subsection{Experiences of success and failure}

The dawn of geomembrane liners in South Africa during the 1960s was led by the use of butyl rubber material in water containment applications, largely for government water supply schemes and power stations. These water retaining reservoir linings made use of mechanical joint systems initially and as technology and polymers evolved into the high-density polyethylene (HDPE), so did the joining systems between membrane sheets develop into vulcanisation and extrusion welding, respectively. These facilities contributed to knowledge and experience which expanded into applications of early industrial lagoon linings which were generally thin geomembranes of mixed polymer installed prior to the development of wedge welding techniques. Many of these installations have served well to this day and some of the examples of unsatisfactory performance have accelerated understanding of lining technology, compared to compacted clay only lining systems.

A barrier system comprises of both drainage, to reduce pressure head, and liner, to give effect to the drain and to control the rate of advection (seepage and diffusion) losses (Rowe et al. 2004).

The use of minimum requirements for negative water balance areas had shown that leachate is produced in waste bodies irrespective of the site water balance. Furthermore, the efficiency of drainage in both negative and positive water balance areas was severely compromised by the lack of filter protection or separation layers between the waste and the aggregate (Shamrock \& Msiza 2015), as well as by precipitate and organic clogging (Legge 1990; Rowe et al. 2004). Similarly, experience in soil mechanics as applied to the clay cores of embankment dams and to tailings dams had emphasised the high variability in performance of fine grained materials with respect to seepage (Cedergren 1968; International Commission on Large Dams (ICOLD) 1986, 1994a, 1994b, 1995, 2013, 2017). Attempts to modify the performance of clays to improve retention characteristics had been met with very limited success both in raw water reservoirs and waste containment clay liners, from which seepage continues to this day and is detected in pressure relief wells or monitoring boreholes, respectively.

This internationally accepted understanding of clay performance was augmented by the knowledge and experience of various geomembranes as used at the time, as well as by international literature, to propose a way forward which recognised the radical change in policies contained in legislation and to match a containment performance with a risk-based waste assessment.

In so doing, the objectives were set to provide significant improved performance of water conservation and pollution control, without substantial cost implications, and requiring a simple set of rules to allow for 
competitive designs employing alternatives, without excluding persons from the already scarce skilled resources of the country. Hence, a graphic based on technological understanding of waste and materials performance in a system, with allowance for alternatives and defined performance was pursued. Although granular drainage layers with filter protection were illustrated, alternative materials of equivalent performance would be allowed for the leachate collection and/or detection systems, and similar for the liner components. Hence, although South Africa had a history founded in butyl rubber and limited PVC membranes, the majority of experience in recent decades had been with HDPE, which was thus selected as the specified liner. Experiences with unproven alternatives promoted by contractors and consultants without complete justification had led to severe negative impacts for facility owners. In both the private and public sector, the use of materials such as flexible polypropylene alloys have, to date, not been proven to be a suitable alternative in all respects, referring to chemical resistance over and above material strength properties. This justifies the regulatory requirement for more than a concept design.

\subsection{Transitional arrangements}

The first concept of barrier systems to be aligned with a new waste risk assessment procedure was presented at Wastecon 2009. The lead authority continued public engagement through multiple forums to present and invite comment on the proposed regulatory system, including cost analysis, resulting in gazetting for public comment in 2011 and 2012, before implementation on 23 August 2013. During this time, several facilities owners and designers embraced the philosophy of water conservation and resource protection, along with the suite of principles and designed facilities in pursuance of such standards. There was, however, an objection based on cost which was largely ascribed to the aggregate of a hazardous waste facility and hence the prescriptive thickness was reduced from 300 to $200 \mathrm{~mm}$, while maintaining the performance criteria of atmospheric pressure. Cost equivalence was achieved and demonstrated for the former hazardous and the now Class A barrier systems, as well as the former medium and large general waste site clay only attenuation liner systems with Class B barrier systems, but the pollution generating medium and small sites were not part of the waste management strategy which looked towards a hierarchy in resultant changing waste stream, abandonment of pollution dilution relying on attenuation and regional sites. This cost equivalence between historic standards and current standards remains true; however, the performance of today's standards at equivalent cost is far superior to the historic philosophies, as recorded above. The containment performance of barrier systems incorporating a composite liner is as much as a million times better than the former clay only liners, the extent influenced largely by construction quality assurance, and noting that for water deficit areas the requirements addressed detection of leachate and not management thereof.

Nevertheless, with the Minimum Requirements 2nd Edition, 1998 classification system, those designs that pursued compliance with what became National Environmental Management: Waste Act (Republic of South Africa 2008) Regulations of 2013 , were given some latitude with respect to compliance with all aspects at the time of submission or application allowing for future address of shortcomings prior to construction. This practice required a significant increase in skilled capacity of the regulators who were called upon not only to provide guidance to license applicants (and their professional service providers), but also to consider multiple amendments to initial designs and additions, such as construction quality assurance (CQA) reports.

Following the implementation of the regulations, there was a peak in demand for license applications which resulted in dissatisfaction over time taken for licensing (Palm \& Visser 2015). This along with other prior constructive criticism by a consultant's registered person of the level of responsibility or power vested in the regulators design reviewer is appreciated, and responses thereto included not only the change from a single reviewer to a panel of civil engineers, but also led to a closer working relationship with the professional body (Engineering Council of South Africa), and other organs of state. A statistical analysis of review periods over the 2016/2017 financial year shows average response time to be 14 days and that this is reduced even further at present but cannot be ascribed only to an increase in capacity but also a further reduction in number of applications lodged. Statistics are now kept to reflect applicant's readiness and 
time-related compliance. The procedures relating to water use license applications have instituted significant reform in efficiencies and the claims of waiting for several months are untrue, however, this has implications for unsubstantiated design proposals.

The challenge resulting today from the transitional period is whether the sites licensed under the Minimum Requirements site classification system can be reclassified under the NEMWA Regulations 2013 system which has a different waste risk profile and barrier performance standard over and above different philosophy. It is worth noting the June 2015 Constitutional Court judgement on the matter between Shoprite Checkers and the Member of the Executive Council for Economic Development, Environmental Affairs and Tourism: Eastern Cape and others, by Messrs Froneman, Moseneke and Madlanga, the following is quoted in respect of a licence:

"Further, licences are subject to administrative withdrawal and change. They are never absolute, often conditional and frequently time-bound. They are never there for the taking, but instead are subject to specified pre-conditions. In time, a licence holder may cease to be suitable to hold the licence and they are also not freely transferable". (Froneman et al. 2015)

The sections leading up to the judgement were extremely interesting in respect of consideration of the Bill of Rights including property, dignity, natural resources, access to food and water and transformation, as shown in the extracts "each individual case must be adjudged within our constitutional framework" (paragraph 39), "There are other similar kinds of potential constitutional entitlements in section 25: to bring about equitable access to all South Africa's natural resources; to gain equitable access to land; and to land restitution. In addition to these land-related entitlements there are specific provisions dealing with socio-economic rights: access to adequate housing; health care services; sufficient food and water; and social security" (paragraph 42), and "Acceptance that the constitutional conception of property may embrace different kinds of entitlements also brings with it the acceptance that, when confronted with legal transitions, the entitlements of the past do not necessarily warrant protection in perpetuity, provided that appropriate and reasonable transitional provisions are made" (paragraph 51).

The reviews undertaken for legal proceedings are not discussed here, however, the principles in law and technology are generally common, to solid, industrial, and mining waste.

\section{$5 \quad$ Lessons from review case histories}

The lifecycle of a waste management facility or similar pollution control facility often spans more than one generation. It is thus obvious that today we are required to address situations for which decisions were made in the past but we live with the consequences thereof today. The following reflections are placed on record to succinctly emphasise aspects of the particular activity.

\subsection{Case 1}

An existing industry was running out of airspace for disposal of waste in the unlined rock quarry with resultant adjacent water resource pollution for which the owner was being held accountable. The entity pursued a risk-based approach to ascertain containment barrier needs, the result of which advocated a triple liner system for this single waste stream. The developer reverted to the Minimum Requirements for a hazardous waste and installed a double composite liner barrier system with leachate collection system (LCS), leak detection system (LDS), and decant to a leachate dam. Sometime after licensing, an amendment was applied for in about 2008/2009 to dispose of additional waste streams being liquid at approximately $95^{\circ} \mathrm{C}$ and another stream rich in calcium. During the then regulators review, the individual sought confirmation from a colleague of the proposed acceptance, and the response is unprintable. A subsequent international expert review was called for with the terms of based on an extract from the Minimum Requirements 1998 which led to the basis of conclusions being, "Fundamental to the study summarised in the report is the premise that provided the leakage through the secondary liner is less than the Department of Water Affairs and Forestry's (DWAF 1998) Minimum Requirements allowable outflow rate of 
$0.03 \mathrm{~m} /$ year ( $822 \mathrm{~L} / \mathrm{ha} / \mathrm{day})$, then the performance of the facility (either the Waste Disposal Area or Storm Water Dam) would be acceptable". The owner continued investigation into performance through the operational life which revealed the extent to which a liner survives installation but can be damaged during investigation, and revealed the limited durability of some geosynthetic components even when covered by a geomembrane (i.e. the geosynthetic clay lines (GCL) carrier component).

This situation reflects the lack of appreciation of elevated temperature effects on service life and of the effects of cation exchange on the GCL alternative to clay component of the composite liner. This shows that it cannot be assumed that all persons involved in decision-making necessarily have all the appropriate technology at hand required for a competent decision. Furthermore, the TOR provided to the expert external reviewer was misleading and assumed the Minimum Requirements specification of a clay minimum performance was the acceptable average pollutant transport, which fails to recognise the superior performance expected of composite geomembrane plus clay liners, let alone the secondary liner and effects of thermal conductivity which are all crucial to understanding the system as a whole and the mechanisms at play. The continued interest and investigation of the owner into the performance of that facility has led to a revised design and improved performance of the next phase, which confirms the value of owner participation in review processes.

\subsection{Case 2}

At a similar period, a different industry with a very high organic content disposed of waste at a clay only lined site and required a footprint expansion. Due to the dolomitic foundation conditions, the expansion employed a precautionary approach and the general site footprint expansion employed a double composite liner with granular LCS, and an alternative material geodrain LDS. The authorised extension pursued an amendment application to address inter alia dust suppression using leachate and a revision of type of waste to be disposed of to include a small rate of hazardous waste deposition. The conditional acceptance included temperature monitoring and the results showed a rapid rise in temperature at the base of the landfill to well over $60^{\circ} \mathrm{C}$. Elevated temperatures can lead to damage of LCSs and composite liners and gas extraction systems, as well as production of odours and increased leachate (Stark \& Jafari 2017; Benson 2017; Reinhart et al. 2017). The subsequent revised operation and monitoring shows leachate at the decant points to be varying around $40^{\circ} \mathrm{C}$. The owner, engineer, and authorities communicate regularly in respect of investigations and alterations with ongoing monitoring of leachate quality, quantity and temperature, while operations are ongoing.

This situation reaffirms the value of regular communication between owners and authorities and the spirit of cooperation required to avoid or minimise environmental and financial impacts. The relevance of international research and technology was confirmed, with the acceptance of parameters and boundary conditions having different influences.

\subsection{Case 3(a) and (b)}

The post-2009 design of a large general waste site pre-2013 and constructed post-2013, as well as a small municipal waste disposal site in the same period, sites formerly classified as GMB- and GSB- both employed a geotextile protected aggregate LCS over a composite liner of geomembrane plus GCL, above a blanket drain. Although adequate clay for a CCL was available on Site 3(b), the motivation for use of a GCL was the speed of construction, and the same motivation was provided to use a geotextile protection layer as alternative to a $100 \mathrm{~mm}$ soil layer above the geomembrane. In both cases, CQA was not put to the competent authority, and the designs were presented after construction completion.

In both cases, the designer did not appreciate the increased hydraulic gradient across the geocomposite liner, nor the effect of the underlying granular drainage layer as a capillary break. Furthermore, the record shows only the geomembrane installer's quality assurance results, but not the owner's independent CQA nor the supervisory engineer's results. It is not surprising that during the operational phase Case 3(a) is considered to result in excessive groundwater pollution and Case $3(b)$ does not show groundwater 
pollution, although the invert level of the waste cell is lower than the operational level of the leachate dam. These designs by the same designer reflect a lack of appreciation of a barrier system being defined by performance of both the drainage layers and the liner layers as individual components and as a system. This is amplified by the leachate dams at these sites not having under drainage (whereas the large cell areas have an expensive under drainage layer), and the result has reflected in one of the sites experiencing hippos or whales beneath the liner of the pollution control dam (where the load on the liner is lower than in the waste cell), and below liner pressures are not adequately resisted by liners with limited or no ballast protection layer.

\section{$5.4 \quad$ Case 4}

A regional municipal solid waste (MSW) facility with design in accordance with NEMWA Regulations 2013 and constructed post-2016 followed a similar single geocomposite (geomembrane plus GCL) liner with geotextile protection layer and LCS, but recognised the importance of pre-hydration and subsurface drainage was provided by strip drains well below the composite liner. The specifications and CQA were addressed as were alternative materials. The geosynthetic products were as in the previous cases reputed for consistency and sound performance. The level of skill required of the contractor was, however, not addressed, and the client chose to not employ independent nor adequate site supervision during site construction. The result was the post construction resistance of the engineer and authority to accept the facility as constructed in accordance with the accepted design and hence an electric leak survey was undertaken. This showed 19 areas of significant damage to the liner which required repair.

The significance of this post construction CQA review demonstrated the extent to which a sound design and good quality geosynthetic materials can be destroyed with resultant non-compliant performance by either the civil contractor and/or lining contractor not being competent and consistent in pursuing performance based standards. It also is an example of the extreme value of electric leak surveys in determining end of construction performance, independent of materials quality.

It would be inappropriate to consider pollution control and waste containment reviews without reflecting on some of the larger applications in mining and coal combustion residue deposits. These sites are usually large footprint areas measured in hundreds of hectares with associated return water dams (RWDs) also known as pollution control dams (PCDs). The pollutant stream is almost always assessed as equivalent to a Type 3 waste risk of the NEMWA 2013 Regulations, although consideration is also given to increasing concentrations of pollutants with time as the processed water is recycled or lost to evaporation.

\subsection{Case 5(a) and (b)}

The coal mining and storage of large volumes of coal for extended periods typically requires a pollution control barrier having performance equivalent to a NEMWA Regulations 2013 Class C barrier, which was pursued for a coal miner and coal user, respectively. The designer pursued a barrier system which at face value appeared to be far higher than the schematic Class $\mathrm{C}$, making provision for a substantive granular LCS of gravel and sand blend approximately $1 \mathrm{~m}$ thick directly on top of a smooth geomembrane plus $\mathrm{GCL}$ composite liner, directly on top of a geotextile and a foundation layer which at these sites was a fine grained sand. Although the designs predated today's regulations and were accepted prior to 2010, their construction was somewhat more recent. A slip failure on first filling with the source material brought the design to the attention of the regulator in Case 5(a). Saturated under drainage and GCL conditions appeared to be prevalent beneath the geomembrane when inspected after exposure. The translational slide took place predominantly, but not entirely, at the geomembrane-GCL interface. A similar design was under construction at Site $5(\mathrm{~b})$ and intervention confirmed the inadequacy of the design with respect to stability.

In both cases the owners, subsequent designer, and reviewers cooperated in pursuing a remedial action. The post failure remedial works amended the address of interface shear and effect of developing undrained foundation conditions, whereas the Case 5 (b) situation amended foundation stability by the introduction of 
profiling the foundations to a saw-tooth of approximately $1 \mathrm{~m}$ height, with the amplitude of increasing distance as the overburden pressure reduced. This revised design approach mobilises the passive resistance of the foundation soil and simultaneously reduces the risk of saturated GCL adjacent to thin near horizontal geosynthetic drainage layers.

These examples reinforce the need for pre-design appreciation of internal and interface shear strengths and the consequences of inadequate drainage or drainage induced conditions. Furthermore, the excessive use of geosynthetics brought about instability, and it could be argued that their presence may have reduced service life. Readers are encouraged to familiarise themselves with the Geosynthetic Research Institute (GRI) Report No. 41 (Koerner \& Wong 2011) addressing case histories of 20 waste facility failures, all of which are related to liquid presence, either in the foundation, in the case of unlined facilities, or above the geomembrane in the case of lined facilities.

\subsection{Case 6(a) and (b)}

The combustion of coal leading to residual ash for stockpiling or disposal leaves a pollutant or waste having a similar risk level requiring the same sort of barrier performance, albeit exposed to a different characteristic leachate. In the Case 6(a), a facility was designed in accordance with the Minimum Requirements Waste Assessment and Commensurate Barrier requirement of a $\mathrm{H}: \mathrm{h}$ prescribed layout. The design proposed and accepted in about 2010 but built after the NEMWA 2013 Regulations incorporated a primary composite liner having a geomembrane of $1.5 \mathrm{~mm}$ thickness and overriding specification defining a particular asperity height for interface shear. The clay component of the composite liner was reduced from the $600 \mathrm{~mm}$ thickness made up of four layers to just $250 \mathrm{~mm}$ thickness made up of two layers of bentonite enriched hill wash sandy material, each being $125 \mathrm{~mm}$ thickness. The LDS was a $150 \mathrm{~mm}$ thick sand layer, given effect by a single layer secondary liner of similar bentonite enriched soil. The overlying geomembrane protection layer is followed by sand filter, considered adequate due to the ash being placed dry.

During construction, a lining contractor experienced what appeared to be separation in plain (SIP) of the geomembrane during pressure testing of the double wedge welded seams. Although the material reflected compliance with South African National Standards (SANS) and GRI standards, the rolls where SIP had been identified were removed and replaced. Nevertheless, samples recovered from the liner by the license holder and regulator were dispatched for third party testing and confirmed compliance with the project specification, however, undertaking tensile strength test at a rate of strain increased to $300 \mathrm{~mm} / \mathrm{minute}$ reflected signs of delamination. It cannot be assumed that this modification of test will identify SIP, but rate of strain and elongation at break may be more informative of polymer used than what is currently understood. Similarly, the use of differential scanning calorimeter (DSC) testing, which plots enthalpy against temperature, will provide curves with peaks associated with the type of polymer(s) in the geomembrane, and the area under the curve reflects the percentage of polymer types in the geomembrane. It is considered prudent to make provision for test methods outside of the norm at the discretion of the facility owner and regulator, as this reduces the risk of products being manufactured to fit standard product test methods, rather than meet the anticipated performance objectives. In respect of the LDS and thin bentonite enriched soil secondary liner it would be unfair to criticise historic decisions; however, it is worth noting that the secondary drainage layer or LDS introduces a capillary break which in turn may lead to accelerated desiccation of the primary liner clay component and simultaneously act as a thermal insulator which would still further reduce performance of the primary liner in the event of heat being generated above the liner. The secondary clay liner would only report leakage when such pollution exceeded the performance of that single layer.

The Case 6(b) ash disposal facility provided a composite geomembrane and CCL liner for its post-2013 Class $\mathrm{C}$ barrier performance, but addressed drainage by way of a composite geosynthetic drain. This design may appear acceptable in principle but the performance was not defined by site specific materials evaluation with particular oversight in respect of filter compatibility between the ash and geotextile component of the thin composite drainage structure, and service life of the drainage structure itself as it undergoes compressive creep collapse and the voids required for leachate transmission do not provide for 
sediment and precipitate. The interface shear and internal shear of the products and materials, particularly under saturated conditions, would lead to some unacceptable Factor of Safety.

This case reaffirmed the need for designers to consider barrier systems as combination of drainage and liners, and the need to address service life of all elements, as well as their combined interaction and internal action.

\section{$5.7 \quad$ Case 7}

The disposal of reworked historic gold tailings proposed a design comprising partial treatment of the tailings to reduce acid forming potential, and disposal at flatter than normal side slopes, i.e. $1 \mathrm{v}: 4 \mathrm{~h}$, to provide for vegetative growth commensurate with the rate of rise, and disposal on natural ground with partial interception of pollutant plume by a perimeter blast curtain and its dewatering by pumping. The motivation for this design was driven by cost comparisons and descriptive statements of geomembrane risks without providing quantification thereof. The design, however, failed to recognise that the partially treated tailings resulted in a leachate which was still a significant pollutant. Furthermore, the designer assumed a far higher percentage pollutant recovery from the blast curtain drain in the short term than the regulator and literature assessment and experience (albeit related to pressure relief wells downstream of dams and pollution migration interceptor curtain), but more importantly did not appreciate a barrier comprises of both drainage and liner (such as a grout curtain), and that the drain had no filter design possibility and could thus not be a once off event. This lack of appreciation for filter compatibility associated with drainage was reflected in the revised design advocating a composite liner with above liner protection provided by tailings, drainage through the use of blast rock or dump rock, and filtration by a light weight geotextile placed directly over the dump rock. Consideration of filter compatibility between hydraulically placed tailings and geotextile filter was absent, as was appreciation of the strength requirements for such material, let alone other short and long-term performance influences as the nature of the retained material changes, and the drain itself reduces in capacity due to biological action and clogging. Such problems associated with precipitate have been reported in literature since investigations at ERGO in the late 1980s (Legge 1990), and is reflected in international guidelines including ICOLD Bulletins on filters and tailings dams.

It is recommended that facility developers or owners make use of independent engineering reviews which report directly to the developer and not to the designer.

\section{$5.8 \quad$ Case $8(a)$ and (b)}

The Minimum Requirements made provision for sludge lagoons by way of prescribing a layout in its Appendix 8.2 (DWAF 1998). Some decades later, the expansion of such facilities is considered and follows the same form as at least the primary liner, the total barrier being defined by the waste assessment. In Case 8(a) an expansion was proposed with significant concern raised due to the increased number of facilities required resulting from the now much slower rate of sludge drying. Drying in new lagoons with a geomembrane base liner retaining the liquids preventing seepage, as desired; however, due to the generally fine nature of sludge the evaporation resulted in limited drying of the upper zone of sludge only. Similarly, in Case $8(\mathrm{~b})$ the capping closure of a sludge lagoon posed challenges with respect to the sludge foundation for the cap being dry to only a limited depth, and the capping loading resulting in what appears to be liquefaction of the lower lying material.

Both of these cases confirmed the significant superior retention of leachate by a geomembrane compared to that of clay only liners, and proved the obvious in respect of seepage rates for a sludge are typically higher than capillary rise and drying by evaporation rates. The exposed black geomembrane lagoon liner designs did not pursue the limited benefit of 10 to $20^{\circ} \mathrm{C}$ lower liner temperature of white reflective layers (Dolez et al. 2017) for the site conditions where exposed geomembrane temperatures regularly exceed $70^{\circ} \mathrm{C}$. 
Although there is resistance to liquid waste disposal, cost savings may be incurred in some situations where sludge requires disposal and drying prior to beneficiation or re-use, or additional facilities. This can be achieved with the use of filters specifically designed for the particular sludge and still further accelerated drainage gained by the application of a controlled vacuum to the drainage layer (Weng 2017). This efficiency has been demonstrated in backfill bag technology where gold tailings within a particular geotextile bag would typically drain in three days, but this period was reduced to three hours through applying a low vacuum to an underlying drain. The theory employed is similar to that applied to prefabricated vertical drains. Designers are advised to refer to GRI Report 46 (Koerner 2017), and to the reference by Dolez and Blond (2017) for further assistance in such situations.

\subsection{Case 9(a), (b) and (c)}

Although designs may be accepted and construction proceed, the design assumptions are put to the test by contractors and supervisory engineers who allow deviation from the design assumptions, or when the design parameters were indicative rather than definitive. In the case of two double composite liner facilities constructed within the past two years, slip failures took place during construction while the LCS of aggregate was being placed over a geotextile cushion layer. Despite the specified materials being used, Case 9(a) suffered a slip failure claimed to be due to the contractor placing the stone aggregate in a downslope direction. Each site specific condition can be analysed to show to what extent either downslope or upslope placing of aggregate can take place before slip failure. The performance of the barrier may be compromised in both cases if strain compatibility and the necking of a geotextile panel is not recognised in the design and taken into consideration in the construction method statement. The claim that hot air gun tacking of geotextile overlap addresses this adequately is refuted, as such specifications are merely descriptive and not performance based. The same situation occurred at Case 9(b); however, the CQA report upon completion of construction raised still further concerns as the report indicated the clays in the primary and secondary composite liners had been compacted up to $10 \%$ wet of optimum moisture content (OMC) which for this site ranged around $22 \%$. The authority considered this impossible and called for confirmation of stability including direct shear using actual materials at the said OMC plus $10 \%$, which the independent testing facility confirmed was impossible to achieve! It is hoped that the designer, independent reviewer and independent laboratory testing facility will in future appreciate the meaning of OMC curves and limits to porosity of a soil, as well as the implications of saturation on consolidated undrained and unconsolidated shear strengths. This investigation did, however, emphasise the need to address rate of rise and density of waste in assessing global and veneer stability. The technology has been practiced in tailings dams for years but has somehow become forgotten when considering other waste streams and containment systems.

The use of international literature and common practice does not, however, negate the need for the designer to apply their mind to the specific circumstances encountered the site under consideration. At Case 9(c) it was assumed that the GCL being of a particular type would not suffer panel shrinkage due to the nature of the carrier material, but this was shown to be untrue upon exposure.

\subsection{Case 10}

An underground chrome mine to the north east of the country was under care and maintenance. The proposed reopening of production required the development of an additional TSF adjacent to the process plant, and three PCDs. The site selected for the TSF was adjacent to a mountain side against which a rising penstock would be installed, and the tailings would be placed by spigot system from a downstream starter wall with an upstream construction. The design made use of a limited geotechnical foundation investigation. The proposed barrier system incorporated a geomembrane liner above a base preparation clay layer, and incorporated a $4 \mathrm{~m}$ wide toe drain specified as a geonet, covered by a woven tape geotextile typically used in mine backfill bag technology, followed by a light weight nonwoven needle punched geotextile as filter, above which the tailings would be slimed. The design report assumed this narrow perimeter blanket drain would draw down the phreatic line adequately for a Factor of Safety greater than 1.3. The design, however, did not 
recognise the incompatibility between nonwoven needle punch geotextile and slimed tailings, which would almost certainly clog with the high fines loading in the slurry. Similarly, the drainage design failed to recognise the extent of geotextile intrusion into the geosynthetic drainage layer and consequent reduced transmissivity, let alone the compressive creep collapse of the geodrain material under a load of approximately $600 \mathrm{kPa}$ over the operational life of the facility. This inadequate drainage of the perimeter wall was further exacerbated by the assumed interface shear of $18^{\circ}$ between tailings and geomembrane, which was based on the designer's experience of unlined sites. The inadequacy of both the drainage system and stability determination led to a change in design team with a consequential capital cost saving to the mining house for a stable and compliant facility situated in a water deficit area where the mining house was dependent on process water augmentation from an adjacent mothballed mine.

\section{$5.11 \quad$ Case 11}

An early gold mine situated in the east of the country has a historic valley fill TSF nearly $300 \mathrm{~m}$ high between toe and crest of the deposit. The proposed reopening of the gold mine included a design for an extension of the TSF incorporating a barrier system having only finger drains above a multi-layer liner, which is far more than what the regulatory standard would require of most mine waste products in South Africa. The liner comprised of a HDPE geomembrane above two GCLs above a foundation preparation layer. The valley fill would continue upstream over the existing TSF. The stability analysis did not include consideration of the valley shape nor the effects of seismicity, and assumed the perimeter wall would be free draining and thus not induce a phreatic line near the toe of the tailings deposition. The stability analysis assumed only a circular slip mode of failure, as the designer again assumed a tailings/geomembrane interface shear value of $18^{\circ}$. No consideration was given to the critical interfaces below the geomembrane being the geomembrane/GCL interface, nor the GCL/GCL interface which could be extremely low and approaching $0^{\circ}$ in the event of saturated bentonite being extruded at this interface. The saturated conditions are quite foreseeable in a valley fill, especially with the upstream historic tailings deposition being unlined and slimed over. Again, a substantial revision using geosynthetic materials appropriately would reduce costs while providing a compliant pollution control barrier for a stable structure in an area without readily available additional water supply. It should be noted that a rapid loading of a saturated sodium bentonite GCL beneath a $1.5 \mathrm{~mm}$ thick geomembrane liner (smooth on both faces) had resulted in consolidated undrained conditions and a sliding failure in a seasonal coal stockyard some years earlier, however, this aspect had not been considered in the design despite publications providing cautionary notes to this effect.

\section{Distinctive solutions for specific situations}

On more than one occasion, design reports in support of license applications have contained disclaimers which states the designer "accepts no liability or responsibility whatsoever for it in respect of any use of or reliance upon this report by any third party" and that no copying of the report is permitted. Such disclaimers render the reports null and void and are returned without consideration.

There are other unusual approaches outside the norm that affects the review consideration which takes a systems approach. Some designs specify performance based on product data sheets without validating the parameters relevance to the particular design, without ascertaining how the parameters change with time or temperature, and occasionally without ascertaining whether such materials are still available or whether technology has surpassed the specified test method, performance standard, material type or interaction with other materials. An example of change with time is the reported change in interface friction between a smooth geomembrane and soil, let alone the change with time to interface shear strengths due to polymer creep or effects of leachate irrespective of texturing. This lack of attention is especially true in respect of filter design for both granular and geotextile filters compatibility with adjacent soils and, in particular, fine grained cohesive soils as used in CCLs (Sherard \& Dunnigan 1989). 
Seldom is consideration given to the difference in performance between the office specimen and the material installed with respect to project specific specifications. The post production storage method can influence geosynthetic performance prior to and during installation, especially for geotextiles (ICOLD 1986), and for GCL carrier components. Observations on a particular day in a supplier's stockyard using an infrared thermometer revealed the following: black plastic sheet wrapping at 70 to $75^{\circ} \mathrm{C}$; unwrapped geotextile rolls at 55 to $69^{\circ} \mathrm{C}$ with colour varying from pale grey to black and the darker the geotextile the higher the temperature, even a red plastic sheet wrapping was cooler at $57^{\circ} \mathrm{C}$; as was the temperature of unwrapped black pipe surfaces which allowed ventilation through the stack.

This makes for interesting assessments when considering the rate of UV degradation, especially on polypropylene (PP) and polyester in relation to thermal conductivity. Similar measurements on geomembranes in Limpopo Province at various sites have shown the upper exposed surface to be at 83 to $86^{\circ} \mathrm{C}$ at midday, and temperatures of 89 to $90^{\circ} \mathrm{C}$ measured in the Northern Cape. A limited drop in temperature of the order of $10^{\circ} \mathrm{C}$ was measured between the upper and lower surface of geotextiles deployed over geomembranes, however, when covered with $100 \mathrm{~mm}$ of soil, the temperature of the liner and number of associated wrinkles reduced significantly. This data emphasises the need for consideration of time-related activities and the consequences thereof, such as the diurnal expansion and contraction affecting the geomembrane/compacted clay liner interface performance, especially when textured geomembranes are employed and the clay surface is effectively combed and soil particles displaced. It is similarly argued that designers should consider the time temperature curve during operation and post operation life, along with the pre-utilisation period so as to give a fair assessment of service life. The use of average temperatures at leachate outlet points is not necessarily a reflection of the containment liner temperature beneath the cell. Such temperatures do not reflect the effect of leachate mounding nor energy dissipation and radiation for which models do exist (Hao et al. 2017) The time temperature service life curve for an HDPE geomembrane being hyperbolic will show that a short period at high temperature can significantly reduce performance far more than the equivalent average temperature of exposure over the same period. Similar time of exposure to temperature and $\mathrm{pH}$ should be afforded to geotextiles when considering the acceptability of polymer (Mathur et al. 1994).

\subsection{Project designs and alternative materials of equivalent performance}

Barrier system designs are required to recognise the waste risk so as to inform the commensurate containment standard and reduced risk to the environment. Understanding the waste risk also requires an understanding of how the barrier system performance will be influenced by the waste material deposition, the way in which the waste mass itself will change with time as leaching or decay takes place if at all, and the consequences of such actions. Most mining waste streams are, however, relatively uniform and well-understood, which should lead to cost-effective containment by skilled and experienced designers. The use of relatively modern geosynthetic materials in barrier systems, be they a regulatory requirement or optional, relies on modern technology which was not available in formal educational structures until the last decade and even then limited to postgraduate engineering studies. Many designers are thus faced with limited knowledge or experience, and may be misled by guidance provided by materials manufacturers or product suppliers which is brand specific and not necessarily relevant to the system being designed. There are distinct perceptions generated in the civil and mining industry which must be tested for relevance in each and every design. Some of these aspects are addressed below.

\subsubsection{Perceived performance of geotextile cushion layers above geomembranes to limit tensile strain}

The regulations pertaining to pollution control barriers provide a schematic layout and suite of requirements to demonstrate performance of a barrier system, which is to be taken into consideration when adjudicating suitability of a barrier system design. The use of geotextile cushion layers as an alternative to sand protection layers, provided equivalent performance is demonstrated is acceptable. In practice, however, a perception has arisen that a geotextile having a mass of $1,000 \mathrm{~g} / \mathrm{m}^{2}$ provides 
equivalent protection to a $100 \mathrm{~mm}$ thick silty sand layer, which is not true for coarse grained and similar puncture producing material. This perception is further aggravated by product suppliers suggesting a hierarchy of needs in decision-making on geotextile selection should be driven by the type of polymer used in geotextile manufacture, be it PP or polyester (PET).

The assessment of maximum allowable tensile strain in geomembranes has been addressed extensively in literature with early suggestions that strains as high as 6 to $8 \%$ in HDPE geomembranes could be acceptable (Peggs 2005). The limit set by the German authority Federal Institute For Materials Research And Testing (BAM) (BAM 2015) of $3 \%$ is generally accepted as the appropriate upper limit, as advocated at the IGS speciality workshop on barrier systems held in Munich, Germany in 2017. It has been shown that the vertical load on aggregate causes tensile strains within the geomembrane which can be measured by short term laboratory tests using lead plates or tin foil to record the deformation (Rowe et al. 2004; Hornsey 2013 ) or by means of calculation. The method advocated by Tognon et al. (2000) is based on a combination of membrane and bending theory, and has been shown to be most reliable (Rowe \& Yu 2019). Although the method advocated by Eldesouky and Brachman (2018) shows promise and is of significant value in that it acknowledges the increased strain effect due to aggregate rotation on slopes. Rowe \& Yu (2019) show that under particular loading conditions, the geomembrane peak tensile strain is related to particle size, with $16 \%$ strain for a $25 \mathrm{~mm}$ particle and $32 \%$ for a $50 \mathrm{~mm}$ particle above the geomembrane without protection layer. They further emphasise the below geomembrane foundation layer influences by showing the 32\% strain for a $50 \mathrm{~mm}$ aggregate above a GM plus CCL layer is reduced to $17 \%$ for a geomembrane/GCL composite liner, for all other variables being held constant. The influence of aggregate or stones within the soil layer beneath a geomembrane should thus not be underestimated. The study further confirmed that a sand layer under the loading conditions reduced the geomembrane strain to $0.2 \%$, whereas for all geotextiles tested as cushion layers, the strain remained above the $3 \%$ limit, but for a particular geotextile of $2,200 \mathrm{~g} / \mathrm{m}^{2}$ the geomembrane strain is limited to $6 \%$. The authors do, however, provide guidance on strain limitation by way of flattening slopes to reduce down drag, reducing above liner interface shear or increasing below liner interface shear or combinations thereof, and noting the effect of wrinkles on performance reduction.

There is a danger in extrapolating one study's results to all designs without recognising the conditions under which the investigation was undertaken. Laboratory test results are influenced by the rate of loading, as for interface shear, the duration of load applied and the temperature at which the test is undertaken.

Further to this, a geotextile protection layer performance will be influenced by its mass per unit area, the type of polymer(s) used in filament manufacture, the length and thickness of filaments including the cross-sectional shape, the form of needling and needling density and the extent of in situ deformation prior to loading. To emphasise the difference in performance of various geotextiles, the parameter of transmissivity or in-plane drainage is used to demonstrate the effect of normal load on transmissivity reduction for a range of variables. Figure 7 (a) to (d) confirms that for the same mass per unit area, there is a significant difference in geotextile performance for materials made of continuous filament PET or staple fibre PP. Similarly, mass per unit area has a significant influence on performance for the same form of geotextile, and for the same resin there is a significant difference between staple fibre and continuous filament performance. Geotextiles having multiple differences in various contributing elements can have significant differences in performance. Specifications should define the performance required and not be limited to a select group of geotextile parameters as this could be misleading. 

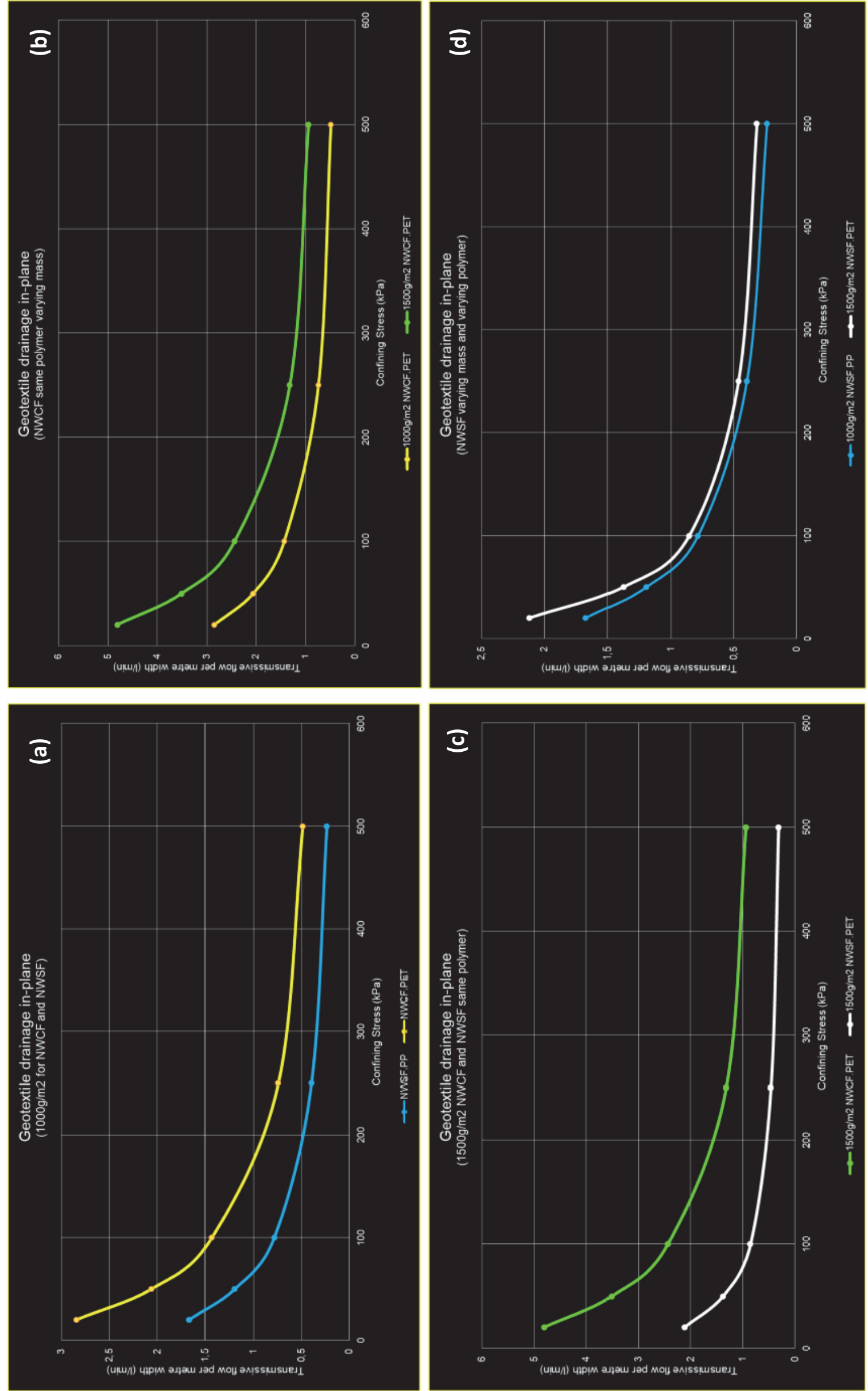

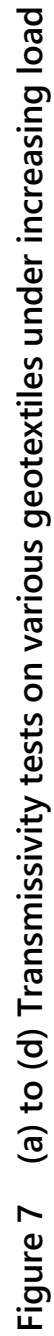


The use of aggregate material in drains to tailings and similar monofill waste disposal facilities is usually limited in extent, but critical to performance of the barrier system and stability of the structure. It has been noticed that size of aggregate alone is not the only parameter influencing strain and geomembrane damage, but the aggregate shape has a marked influence due to both the type of point load and the workability during placement. Aggregate shape can be influenced by the type of crusher be it a jaw breaker or rotary crusher for the particular type of rock, however, the post crushing treatment by rolling with a bow-mag roller compactor can significantly reduce particle sharpness and improve roundness. Similarly, the placement of aggregate drainage layers have been found to be a significant contributor to construction damage leading to tears rather than the commonly assumed holes which if undetected would render assumed leakage rates misrepresentative. These incidents can, however, be reduced by defining the means of placement and spreading of aggregate to ensure aggregate is dumped on aggregate before being distributed by a tract vehicle rather than low pressure wheel vehicle (to avoid turning induced torsional tears) and post placement electric leak location surveys (Beck 2015; Rowe \& Yu 2019). It is postulated that the fines or dust on aggregate that washes into the geotextile protection layer receiving face leads to a stiffening of the geotextile layer and improved performance as applied load increases, however this is still to be quantified. Figure 8 shows typical damage induced during spreading of protection layers or drainage aggregate, as well as the fines and dust component that may accumulate at the geotextile aggregate interface when unwashed aggregate is used in drainage applications.
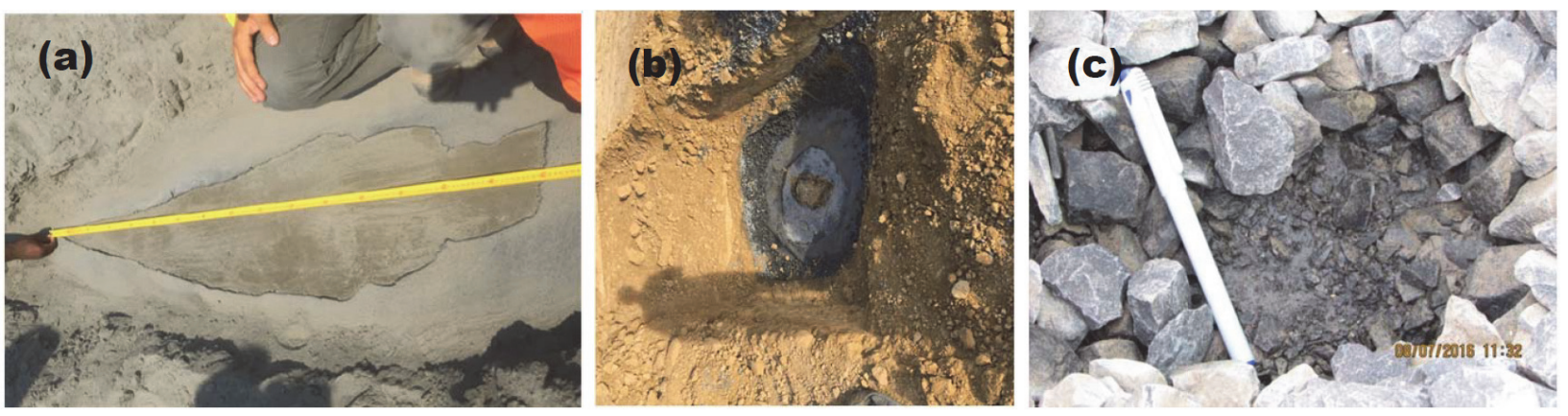

Figure 8 (a) Tear induced by material shearing (platinum TSF); (b) Rotational tear induced by wheel turning; (c) Dust penetration of a geotextile protection layer interface

\subsubsection{Perceived performance of geosynthetic clay liner layers as alternative to compacted clay liners (CCLs)}

The potential benefit presented by GCLs as partial or total replacement of CCLs has been advocated for two decades, and multiple investigations into performance of GCLs has been published to address the concerns of designers who have had confidence in their knowledge and use of clay liners, particularly when related to dam engineering. The performance of such composite liners has been evaluated and assessed for a range of conditions (Foose et al. 2001; Rowe 2005, 2011, 2012). Today there are some perceptions that a GCL offers only beneficial use without recognising the limitations or a detailed investigation of the site specific performance requirements. Recent developments in which GCLs are improved by the addition of polymers or bentonite modifiers to compete with sodium bentonite based GCLs have had a further influence on perceptions.

It is noted that the inclusion of a blanket drain beneath the clay component of composite liner subjected to elevated temperatures, such as in heap leach pads and some mineral deposits, will probably lead to desiccation and reduced performance of mineral clay liners (Doll 1997), and similarly for GCLs (Acikel et al. 2018; Lu et al. 2018) further compounded by the effect of salts and cations in the permeant.

It is commonly perceived that there is adequate moisture in the soil above or below a GCL, such as in capping and base liner applications, to ensure adequate hydration of the $\mathrm{GCL}$ to ensure equivalent performance to a $600 \mathrm{~mm}$ thick CCL. This is not possible in composite liners above capillary breaks or drainage layers nor in double composite liner facilities (Legge et al. 2007), and may not be true for 
applications where the $\mathrm{GCL}$ is in direct contact with adjacent soils that have not been compacted with adequate moisture content or soils containing smectite. In such cases the degree of saturation may be even lower than the 30 to $70 \%$ typical of application in contact with non-cohesive soils (Rowe 2018).

It may be presumed that a GCL advective performance is defined by the bentonite content and not the method of manufacture, which may be true irrespective of particle size (granular or powdered) provided that the GCL is under high confining stress, the bentonite is from the same source, the products have the same mass per unit area, and the bentonite is at the same degree of saturation. It is most unlikely to have these four parameters constant for different GCLs. Rowe (2018) notes that the GCL structure can significantly influence the moisture content of the bentonite at the low confining stresses typical of the hydration phase, and thus finer may be better. Even this suggestion may not hold true for facilities in which containment is required soon after installation - because the wetting front through a GCL is higher for granular than powered bentonite, and thus it may be preferable in some situations where the pollutant receiving face is on the opposite side of the GCL to the wetting face to make use of less finely ground bentonite.

Installation guidelines from GCL manufacturers usually recommend covering of a GCL within a timely manner to overcome panel shrinkage, the risk of which can be further reduced by specifying GCLs incorporating a scrim in their structure. The timely manner is ill defined and may be influenced by a range of factors including the moisture retention curves for the particular bentonite, local climatic conditions and nature of materials adjacent to the GCL. While it is good practice to cover a GCL with a confining stress (which usually reduces induced temperature and moisture loss as well) on the same day as placement, this may not always be practical in which case a more careful selection of $\mathrm{GCL}$ and alternative construction methodology may be required to limit loss in performance.

\subsubsection{Perceived performance of geosynthetic filters and drains as opposed to granular filters}

It is believed that a geotextile may be used as a replacement to filter sand in tailings and return water dam facilities or similar. This may be true provided the filtration and drainage system as a whole remains functional throughout the operational life and post closure service life requirements, including incidents of earthquake loading or tremors and liquefaction. Again, there are a lot of caveats. Post construction filter and drainage performance does not have the benefit of performance evaluation prior to use that geomembrane liner systems have by way of electric leak location surveys (Beck 2015). So too is it important to recognise the extent of filter compatibility between waste material or tailings and the underlying material, particularly at holes or discontinuities in geomembrane lined facilities. Chou et al. (2018) identify a critical stress condition where piping of tailings occurs through geomembrane defects where the underlying foundation or embankment soils do not meet conventional filter criteria which could lead to underestimation of leakage and of pore pressures within an embankment.

The use of data sheets for design of geocomposite drains fails to recognise the effect of intrusion into synthetic drainage cores (Legge et al. 2014, 2015), which could lead to similar unacceptably high pore water pressure and reduced stability Factor of Safety. The loss of stability may be further aggravated in designs failing to take cognisance of the site specific probability of seismic events for dams (Singh et al. 2010), and the effect of dynamic displacement on geosynthetic interface shear strengths which may be greater or lesser than static state values for various seismic events (Pavanello et al. 2018).

\subsection{Project specifications}

Design reports have been submitted claiming safe structures based on a single interface shear test. Still other designs have been submitted in support of license applications with a claim that stability will be addressed only after tender award or during construction. The failure to recognise the importance of interface shear limitations, and the effect of saturated conditions and strain compatibility poses an unfair risk and liability on the facility owner - the facility being either unsafe or having excessive conservatism. 
In a particular facility in the coal mining industry, a low risk waste stream was provided with a single geocomposite (LLDPE-S and GCL) liner with substantial overlying granular drainage layer. The authority's rejection of the design based on unproven stability resulted in confirmation of a Factor of Safety of 1.0 for the PCDs under construction. The challenge faced then was that the facility was under construction in advance of authorisation or licensing. Hence, the regulator advised the applicant to profile the base of the intermediate walls in a saw-tooth cross-section so as to mobilise the base material shear strength. The consulting engineer embraced the concept and optimised the profile with increasing wave length between saw-teeth as the embankment wall height reduced above the composite liner. It is considered good practice to include drainage trenches and berms in line systems so as to increase stability.

Recognition of interface shear limitations and managing the slip surface above the containment liner in designs incorporating geosynthetics is not adequate to ensure stability. The construction of composite (geomembrane plus CCL) liners in which the clay component compaction specification is $98 \%$ Standard Proctor maximum dry density (MDD) at minus $1 \%$ to plus $2 \%$ OMC can be compromised if construction takes place at excessive moisture contents. The pursuit of particular specifications requires justification. The multiple failure of various HDPE geomembrane products at a particular water storage reservoir, emphasises the need to consider the nature of the material to be contained, especially the presence of oxidising agents, notably before construction. The same can be said for specifying drainage material and interface shear strength. The specification of an asperity height does not define interface shear for geomembranes. The texturing through micro-spikes or other features is dependent on more than just height, and is influenced by the density, stiffness and nature of the texturing in relation to the adjacent material and similar. Table 3 provides a comparison between two series of interface shear results for a range of geomembranes having different micro-spike height and density of distribution. The nature of soil selected for the test series was a low permeability clay typically used in CCLs, and an ash as these are typically found in large facilities. The author reiterates the caution in literature that actual interface shear tests should be undertaken to determine strength parameters, and furthermore supports the concept of multi-layer shear box tests (Khilnani et al. 2017) to reflect not only interface but also internal stress strain relationships of materials. It is erroneous to assume a particular height of micro-spike will provide the highest interface shear, or even adequate interface shear strength.

Table 3 Interface shear results for five geomembrane types of different micro-spike height and distribution with a particular compacted clay and a particular ash, under different normal stresses (acknowledgement H Venter, NAKO LBE (Pty) Ltd for sponsoring the test series)

\begin{tabular}{|c|c|c|c|c|c|}
\hline \multirow[t]{2}{*}{$\begin{array}{c}\text { Test } \\
\text { number }\end{array}$} & \multirow{2}{*}{$\begin{array}{l}\text { Textured } \\
\text { geomembrane } \\
\text { micro-spike } \\
\text { height (mm) }\end{array}$} & \multicolumn{2}{|c|}{$\begin{array}{l}\text { Clay at interface } \\
\text { MDD } 1,509 \mathrm{~kg} / \mathrm{m}^{3} \\
\text { OMC } 26.5 \%\end{array}$} & \multicolumn{2}{|c|}{$\begin{array}{l}\text { Ash at interface } \\
\text { MDD } 1,130 \mathrm{~kg} / \mathrm{m}^{3} \\
\text { OMC } 40.7 \%\end{array}$} \\
\hline & & $\Phi\left({ }^{\circ}\right)$ & $\mathrm{C}(\mathrm{kPa})$ & $\Phi\left({ }^{\circ}\right)$ & $\mathrm{C}(\mathrm{kPa})$ \\
\hline 1 & $0.40^{*}$ & 8.3 & 12.8 & 27.8 & 16.5 \\
\hline 2 & 0.65 & 9.4 & 7.5 & 36.2 & 40.8 \\
\hline 3 & $\geq 0.9$ & 8.4 & 10.5 & 39.9 & 3.7 \\
\hline 4 & $\geq 0.9$ & 7.2 & 13.1 & 35.8 & 7.8 \\
\hline 5 & $\geq 0.9$ & 8.5 & 6.8 & 40.8 & 0 \\
\hline 6 & 1.1 & 9.4 & 18 & 38 & 13.7 \\
\hline
\end{tabular}

Shear tests undertaken at normal loads of 20, 200 and $400 \mathrm{kPa}$.

*Texturing is a random full surface treatment, not spaced micro-spikes. 
The previous results confirm specification that micro-spike height alone does not define maximum interface shear strength benefit. The influence of polymer enriched bentonite GCLs on interface shear strength reduction is reported by Chen et al. (2017). The reason therefore considered as being due to the extrusion of polymer hydrogel under confining load. The effect of anions on increasing permeability of bentonite-polymer GCLs (Tian et al. 2017) is not addressed in the cases referenced previously, nor is diffusion through such BP GCLs, as reported by Sample-Lord et al. (2017).

\subsection{Construction quality assurance}

It is an increasingly common practice to include material specifications in the CQA part of a design report. While these specifications on occasion contradict the specifications on the engineering drawings, there are occasions where particular specifications amend standards and test methods without technical substantiation. The specification of a particular ash content, standard and/or high-pressure oxidation induction time (OIT), does not necessarily add value to the design (Ewais et al. 2014), but does tend to increase costs by exclusion of materials that comply with standards. Furthermore, no justifiable reason is provided for deviating from the rationale behind the GRI GM13 standard specification for geomembranes (Hsuan et al. 2015) in almost all particular specifications of deviation. In addition, these limited specifications are indicators and do not inform the design with respect to polymer or resin itself.

The DSC test holds invaluable insight into what the black geomembrane is made up of (Figure 9). The peak temperature at a transition such as at melt temperature is characteristic of a polymer, e.g. polyethylene (PE) or PP etc. By observing the DSC plot of energy absorption versus temperature for a particular polymer sample we can identify with some surety from the peak or multiple peaks what the sample is made up of, e.g. a blend of PE and PP. The area under the bell curve gives the comparative percentage of makeup of the specimen. The position of the peak reflecting the thermal transition temperature may give insight into the makeup of resin blends and crystallinity, as PE is generally grouped into three broad classes of high-density, linear low-density, and low-density polyethylene, each with its own attributes. The DSC will, however, not identify the presence of inclusions such as polycarbonate nor polystyrene.

The interpretation of such DSC results requires careful consideration with respect to the particular application. It is known that some thin (less than $1 \mathrm{~mm}$ thickness) blended geomembranes have served as satisfactory lagoon liners for decades under exposed South African conditions to hazardous substances including hydrocarbons. Still other geomembrane liners of HDPE have failed under exposed South African conditions when serving as merely potable water containment. Although in these applications the geomembrane is accessible for repair, they are included for an appreciation of the complexity in assessing liner suitability for particular applications. The type of geomembrane and its specific formulation is critical to its longevity (Koerner \& Koerner 2017). It is recommended that the owner of a facility makes provision for geosynthetic performance evaluation at the discretion of themselves and/or reviewers, including the statutory review in particular, to enhance assurance in the materials being procured for projects. Such truly independent considerations may include analysis using DSC, gas or liquid chromatography mass spectrometry, infrared scanning or the EU 10/2011 test. It is noted that a resin including calcium carbonate has been offered in the plastics market which would have a significant detrimental effect on service life performance. The value of thermogravimetry tests as used for determining carbon black but undertaken at even higher temperatures (approximately $900^{\circ} \mathrm{C}$ ) should not be underestimated.

It is generally accepted that the higher the crystallinity (and associated transitional phase temperature), the more chemically resistant the geomembrane (Rowe et al. 2004, p. 524).

Significant variation has also been recorded in OIT test results, both prior to and post installation (Morsy \& Rowe 2017) have reflected on service life variability for blended polyolefin geomembranes in respect of standard OIT although service life depends on the entire antioxidant package, polymer resin, and incubation media.

It is thus recommended that the CQA report demonstrating compliance of the as-built facility with the accepted design should include not only the as-built drawings, but also the type of test, number of those 
tests undertaken; the maximum, minimum, mean values and standard deviation for the test method and an indication of where the tests were undertaken. This record should be for all materials - natural and geosynthetic, and include the aggregate leachate collection and detection systems where relevant. Similarly, an evaluation of geomembrane performance relative to standard or project specific specifications of OIT (standard and/or high pressure) should be sensitive to variation in results for the same material tested in a single machine or single laboratory or different laboratories. The results may be influenced by the machine, the operator or any contamination of the extremely small specimen $(5 \mathrm{mg})$ by hydrocarbons or even finger oils. Reliance on ISO standards for manufacture is not adequate to define performance, as shown over the past five years during which ISO 9001 geomembranes have twice been supplied from European Manufacturers which upon installation have not met performance specifications, including visually obvious discontinuities (Figure 10).

Descriptions provided by an independent CQA monitor are not adequate, and have been known to not reflect the offsite stored data. This aspect has brought the definition of independence into question.

The value of electric leak survey and/or electric LDS can thus not be underestimated.

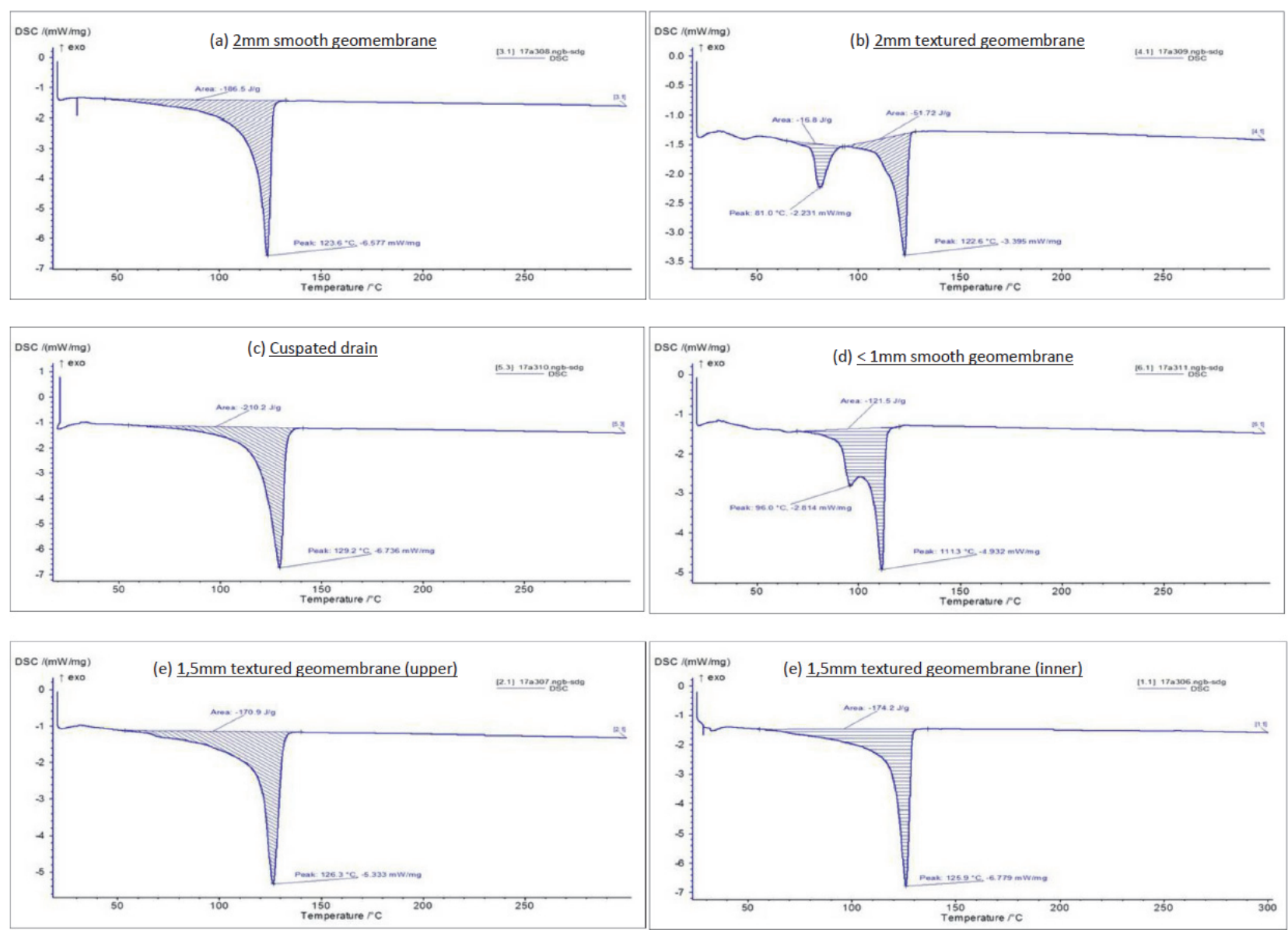

Figure 9 Differential scanning calorimeter (DSC) test results for five HDPE geomembranes used in containment facilities with temperature peaks at (a) $123.6^{\circ} \mathrm{C}$; (b) $81.0^{\circ} \mathrm{C}$ and $122.6^{\circ} \mathrm{C}$; (c) $129.2^{\circ} \mathrm{C}$; (d) $96.0^{\circ} \mathrm{C} ; 111.3^{\circ} \mathrm{C}$; (e) $126.3^{\circ} \mathrm{C}$ (upper) and $125.9^{\circ} \mathrm{C}$ (inner), confirming the range of polymers and crystallinity

It is with some disillusionment that design report and drawings do not reflect instrumentation to the extent typical of other engineering structures. The absence of site boundary definition, strain gauges, thermistors and flow gauges places the facility owner at risk in many situations. Similarly, the failure to address critical elements of barrier systems such as drainage pipes, drainage cores, sump liners, and filter materials to the 
same level surety as geomembranes, clays or GCLs introduces weaknesses in design and performance of barrier systems.
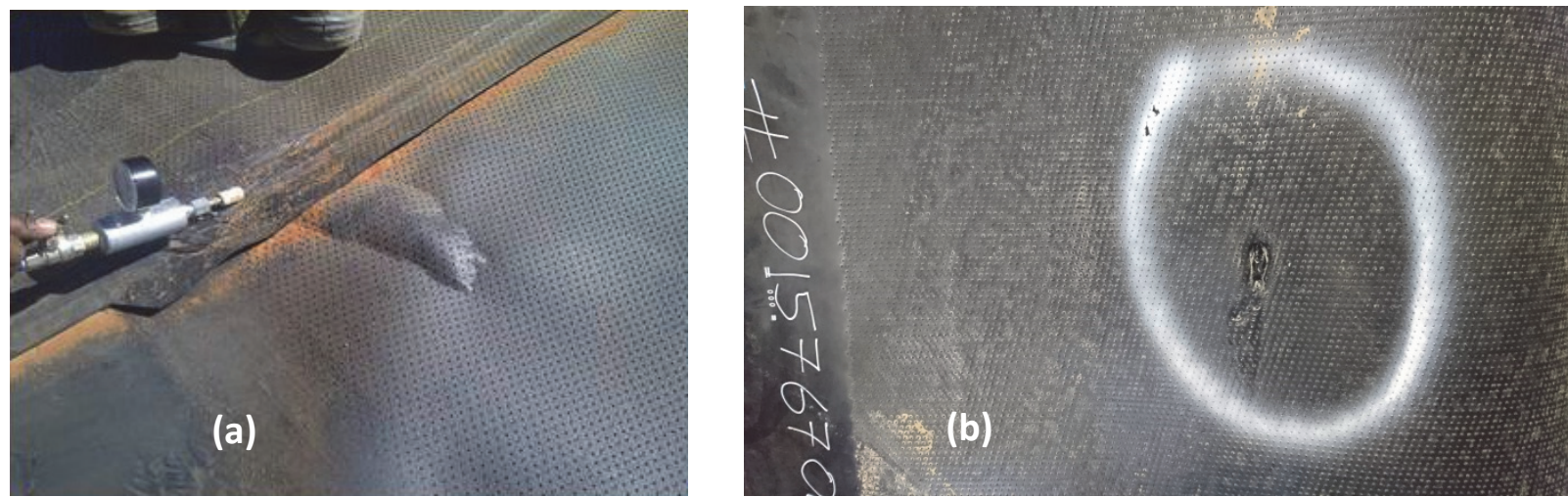

Figure 10 Geomembranes manufactured to ISO 9001 but shipped and revealed deviations from performance during construction; (a) Separation in plane adjacent to wedge welds; and (b) Discontinuities in texturing and thickness to the extent of manufactured holes

\section{$7 \quad$ Equity and sustainability}

The regulator has on occasion been challenged on fairness and consistency of decision-making. There does, however, need to be a clear separation of roles and responsibilities between the designer and the regulator. This is emphasised particularly in forensic analysis following geotechnical structure failures such as of a tailings dam (Morgenstern et al. 2015). The reliance on observational methods and government inspections alone is inadequate to avoid many an incident, because no amount of inspection will reveal the hidden flaws. Hence, further actions may be prescribed from time to time. Nevertheless, it is axiomatic that the regulator cannot regulate its own activities, and if the regulator were to usurp the role of the designer it would usurp its own role. Thus, reviews result in an assessment of acceptability, whereas the designer is responsible for the approval of reports and drawings.

\subsection{Principles of review decisions}

The National Environmental Management Act, Act 107 of 1998, (Republic of South Africa 1998c) defines the principles to be taken into consideration when considering actions which may significantly affect the environment.

These principles are:

- Consistency: the principles apply throughout the Republic of South Africa (RSA) and to all organs of state (2.1).

- Equitably: environmental management must put people at the forefront of concern and serve their needs equitably (2.2).

- Sustainability: development must be socially, culturally and environmentally acceptable (2.3).

- Impact avoidance: impacts on biodiversity, pollution, landscape, resource depletion, people's rights and waste generation must be avoided, and where unavoidable be minimised and mitigated recognising a risk averse and cautious approach. (2.4a) best practical environmental option (2.4b).

- Environmental justice: an adverse impact shall not disadvantage other persons, especially the previously disadvantaged and vulnerable (2.4c).

- Equitable access: all persons shall have fair access to resources, even if special measures are to be taken to facilitate previously disadvantaged persons (2.4d). 
- Responsibility: responsibility must be maintained throughout the activity life cycle (2.4e).

- Participation: processes must be inclusive and provide for capacity building where necessary (2.4f).

- Inclusive decision-making: decisions must recognise person's interests, needs, values and all knowledge of interested and affected parties (I\&Aps) (2.4g).

- Environmental Education: Community wellbeing and empowerment must be encouraged through knowledge sharing (2.4h).

- Complete consideration: decisions must reflect consideration, assessment and integration of disadvantages and advantages (2.4i).

- Right of refusal: workers may refuse to do dangerous work and should be informed of dangers (2.4j).

- Transparency: access to information must be in accordance with the law (2.4k).

- Harmonious policies: there must be intergovernmental coordination and harmonisation on policies and actions (2.4l).

- Conflict resolution: actual or potential conflicts between organs of state should be resolved procedurally $(2.4 \mathrm{~m})$.

- Global interests: global and international responsibilities are to be discharged in the national interest $(2.4 n)$.

- Public trust: environment beneficial use must serve public interest and be protected for common heritage (2.40).

- Polluter pays: costs of remediation and of preventing, controlling or minimising further pollution and health impacts must be paid by those responsible for harm (2.4p).

- Recognition of women and youth: the vital role of women and youth must be recognised and promoted (2.4q).

- Ecosystems require special attention: specific attention shall be given to stressed, vulnerable, highly dynamic and sensitive ecosystems (2.4r).

The central guiding principles of the National Water Act, Act 36 of 1998, (NWA) are equity and sustainability in the protection, use, development, conservation, management and control of water resources. Chapter 1 of the Act provided interpretation and fundamental principles to be applied, whereas Chapter 4 guides responsible authorities in the exercise of their discretion when granting a licence and conditions attached thereto.

Furthermore, registered persons in terms of the Engineering Professions Act, Act 46 of 2000 (Republic of South Africa 2000), are required to abide by a code of conduct as defined in Board Notice 41 of 2017 (Engineering Council of South Africa 2017), which requires designers and reviewers to inter alia take public interest and the environment into consideration, and form opinions based on fact.

\subsection{A systems approach to review}

The revised legislation and waste strategy moved away from dilution of pollution and reliance on attenuation, now relying entirely on containment. The assessment of waste streams remaining after reduction and re-use, leads to five classes of high risk (hazardous); medium risk (general); low risk (dilute); and inert waste. The class of waste posing highest risk may be assessed as Type 0 requiring pre-treatment before disposal, followed by Types 1 to 4 for decreasing risk waste or pollutant. The high, medium and low risk waste streams now require a commensurate high, medium and low standard of containment barrier system. 
The National Water Act, Act 36 of 1998, has further aspects to be taken into consideration for a water use license or general authorisation, one of which being water conservation.

All waste facilities are required to have a barrier system comprising of both a drainage and a composite liner system. The performance of the barrier system required reduces with commensurate reduction in risk to the environment. The facilities for high risk waste are required to have double composite liner separated by a LDS, whereas the medium and low risk waste containment facilities require a single composite liner.

The performance of barrier systems has been a subject of debate for decades. Early theoretical estimates by Giroud et al. (1994) (Table 4) may overestimate the competence of composite liner systems. The influence of substandard CQA and in particular the effect of wrinkles (Rowe 2012) in generating discontinuities and reducing the area of direct contact between geomembrane and clay component will significantly reduce performance. It is postulated that if a particular site supervision and construction team cannot undertake competent liner installation, it similarly cannot undertake competent multiple clay layer construction. This is particularly evident where density tests are undertaken on compacted soil layers above geosynthetic layers without either a specification or control of the depth to which the peg is driven when performing the hole for radioactive measuring devices and the lack of attention to specified remediation of the test hole in the clay, let alone the punctured geosynthetics.

Table 4 Theoretical leakage rate per unit area in litres per hectare per day (I/ha/day) through various types of liners (Giroud et al. 1994)

\begin{tabular}{cccccc}
\hline & \multicolumn{5}{c}{ Hydraulic head $\mathbf{h}(\mathbf{m})$} \\
Liner type & $\begin{array}{c}\text { Soil hydraulic } \\
\text { conductivity k } \\
\text { ( } \mathbf{m} / \mathbf{s})\end{array}$ & $\mathbf{0 . 0 1}$ & $\mathbf{0 . 0 3}$ & $\mathbf{0 . 1}$ & $\mathbf{0 . 3}$ \\
\hline Soil & $10^{-7}$ & 90,000 & 90,000 & 100,000 & 150,000 \\
& $10^{-8}$ & 9,000 & 9,000 & 10,000 & 15,000 \\
Geomembrane & $10^{-9}$ & 900 & 900 & 1,000 & 1,500 \\
Geomembrane on & $>10^{-2}$ & 600 & 1,000 & 2,000 & 3,000 \\
semi-permeable & $10^{-3}$ & 300 & 500 & 1,100 & 2,000 \\
medium & $10^{-4}$ & 100 & 250 & 600 & 1,400 \\
Geoclay & $10^{-5}$ & 40 & 100 & 200 & 600 \\
Composite liner & $10^{-6}$ & 10 & 20 & 60 & 150 \\
with compacted & $10^{-11}$ & 25 & 50 & 150 & 450 \\
soil layer & $10^{-7}$ & 1.5 & 4 & 12 & 30 \\
Composite liner & $10^{-8}$ & 0.3 & 0.7 & 2 & 6 \\
with geoclay & $10^{-9}$ & 0.05 & 0.15 & 0.4 & 1 \\
\hline
\end{tabular}

The extent to which total solute transport of pollutants migrate through a barrier system is, however, influenced by both seepage and diffusion (Foose et al. 2001) and designers have tended to ignore the effect of diffusive losses through even perfectly intact geomembranes. So too does the temperature of the liner influence transport losses (Rowe 2005), but of immense significance is the extent to which intimate contact is achieved between the geomembrane and adjacent flow restriction layer (Rowe 2012), which is largely why composite liners incorporating a $\mathrm{GCL}$ are superior to composite liners incorporating a $\mathrm{CCL}$ with all other factors remaining the same. This philosophy allows realisation of significant cost savings in the mining industry when considering flownets around points of discontinuity beneath TSF (Rowe et al. 2017). 


\subsection{Competitive procurement}

The intention is to note the development of recent practices which are believed to be anti-competitive and have an element of corruption which has a negative impact on both the environment and business practices. It is in response to these practices that legal guidance is sought with intent to rectify such practices, albeit through criminal prosecution and/or approaches to the relevant ombudsman.

The competent authority for waste management and water use licensing is the Department of Environment Affairs and the Department of Water and Sanitation, respectively. Both state departments are bound to cooperate by sections $41(\mathrm{~g})$ and $(\mathrm{h})$ of the Constitution of the RSA and sections 44 and 49 of the National Environmental Management Waste Act, and they employ the National Environmental Management Waste Act, Act 59 of 2008 Regulations of 2013 (Republic of South Africa 2008) for assessing waste or pollutant source and the commensurate pollution control barrier standards.

These regulations, known as NEMWA Regulations 2013 R636 national norms and standards for waste disposal by landfill, prescribe the use of geomembranes and allow the use of other geosynthetic materials as replacements for natural materials provided equivalent performance has been demonstrated (NEMWA R636 regulation $3(2)(d)$ ). This regulation also requires license applicants to submit signed design reports and drawings by an Engineering Council of South Africa registered person, in support of a license application, and include a CQA plan for implementation during construction.

The alternative materials include possible use of different geomembranes, geotextiles, geodrains and geocells. Alternative materials are not necessarily required, nor the cheapest option, if suitable natural materials occur onsite. License applications often exclude geotechnical evaluations of available materials which meet prescribed performance specifications in favour of geosynthetic products. License applicants should insist the engineer demonstrate cost-effectiveness of the design, or have an external audit to identify such oversight, accidental or intentional, by the designer.

For years the industry has attempted to specify performance; however, where products brands have been specified, professional engineers have included words such as 'or equal', 'or equivalent', 'or similar'. The Geosynthetic Interest Group of South Africa (GIGSA) published a newsletter article to this effect in November 1999 (GIGSA newsletter November 1999, Fairness Associated with Specifications).

This approach for fair and competitive behaviour in the engineering industry is carried through in more recent legislation. The purpose of modern legislation is to promote and maintain competition in the RSA, for efficiency adaptability and development of a country; to provide consumers with competitive prices and product choices; and to promote employment and advance the social and economic welfare of South Africans.

There is a growing perception, if not reality, of alignment between players in the industry. This may be through the over-specification or exclusionary specifications of the consulting engineer targeting a particular product or product supplier. The practice has further developed in which product suppliers have preferential or exclusive supply relationships to installation contractors. The implications are that an applicant's ability to get a fair competitive price for a waste management facility is placed in the hands of the consultant who through specification is actually specifying the contractor and controlling the price rather than the facility performance.

Restrictive horizontal practices and restrictive vertical practices address agreements between firms or associations of firms and are prohibited if competition is lessoned, unless it can be shown that competition is improved and/or technical advantage outweighs restriction. Similarly, it is prohibited to directly or indirectly fix a trading condition, divide markets and collude in tendering.

The abuse of dominance by a firm is prohibited, such as to charge an excessive price to the detriment of consumers, to refuse a competitor access to an essential facility when it is economically feasible to do so, to engage in an exclusionary act unless the technical advantage or pro-competitive benefit can be shown to outweigh the anti-competitive effect (Competition Act, Act 89 of 1998, section 8; Republic of South Africa 
(1998a)). Such outlawed acts include requiring or inducing a customer or supplier to not deal with a competitor; refusing to supply scarce goods to a competitor; and/or selling goods or services on condition that the buyer purchases separate goods or services unrelated to the object of a contract. This applies to all business in South Africa, public and private.

It is understood that all state-owned entities and government departments are also required to comply with the Public Finance Management Act (PFMA), Act 1 of 1999 (National Treasury of South Africa 1999), Treasury Regulations (http://www.treasury.gov.za/legislation/pfma/regulations/default.aspx), and the Treasury Guidelines (http://www.treasury.gov.za/legislation/pfma/guidelines/default.aspx) in respect of those regulations.

The guidelines on Supply Chain Management: A Guide for Accounting Officers/Authorities of 2004 (National Treasury of South Africa 2004) state on page 27 clause 3.4.2:

Specifications should be based on relevant characteristics and/or performance requirements. References to brand names, catalogue numbers, or similar classifications should be avoided. If it is necessary to quote a brand name or catalogue number of a particular manufacturer to clarify an otherwise incomplete specification, the words "or equivalent" should be added after such reference. The specification should permit the acceptance of offers for goods which have similar characteristics and which provide performance at least equivalent to those specified. The quality of goods/services require should, however, not be over-specified to the extent that it will be impossible for others to offer such a product.

Furthermore, on page 36 thereof a table addressing the use of brand names is explicit in repeating the quoted clause 3.4.2.

It is clear that the over-specification to preclude other competitive product suppliers is unacceptable, as is the use of brand names without allowing alternative products of equivalent performance for organs of state.

In tender documents for both public and private entities, some engineers specify materials such as geomembranes and GCLs and geosynthetic drainage layers to the extent that only a single producer can supply such materials. Consideration of local natural materials and local construction and manufacturing is not addressed in design reports.

There is a duty upon all officials in a department, trading entity or institutional institution to take effective or appropriated steps to prevent any unauthorised expenditure, irregular expenditure and fruitless or wasteful expenditure.

For all organs of state, it is appropriate for chief finance officers (CFOs) to instil a practice of auditing specifications in waste containment facilities, where product specifications deviate from regulatory norms and standards. Similarly, it is good practice for the private sector waste management facility (WMF) license holder to have design reports, drawings and tender documents audited or reviewed by a party independent of the design engineer and without vested interests of any sort to review such, specifically for the purpose of cost-effectiveness.

\section{Distinctive waste streams and containment systems}

\subsection{Brine and acid lagoons}

In the gold and coal mining industry, liquid waste streams with high concentration of salts or strong acids are occasionally produced. Such liquid waste streams are generally considered difficult to contain due to the reaction between the liquid waste and clay or similar material. 
It is noted that the brine discharge into the PCD is not the concentrated condition representing the leachable concentration threshold, but rather that the end of evaporation period represents the waste type to be contained for pollution prevention.

The historic MR2 of 1998 lagoon standard, or NEMWA Type 1 waste Class A barrier system design, could be made acceptable provided the performance of alternative barrier system and hydraulic gradient across the alternative to primary composite liner is demonstrated as having equivalent performance to that of a Class A barrier system.

The requirements for waste containment in the norms and standards (Republic of South Africa 2008: R636 of 2013 Norms and Standards for Disposal to Waste to Landfill regulation 3(1) and 3(2)) require the authority to consider Pr.Eng. signed design reports and drawings with alternative materials provided equivalent performance is demonstrated.

It is known that sodium bentonite GCLs react negatively to cation exchange (Elges 1985; Scalia \& Benson 2011) and to salts. Furthermore, the hydraulic gradient across thin geocomposite liners ( $2 \mathrm{~mm}$ thick geomembrane plus $6 \mathrm{~mm}$ thick $\mathrm{GCL}$ ) or geomembrane only liners is orders of magnitude higher than across a composite ( $2 \mathrm{~mm}$ thick geomembrane plus $600 \mathrm{~mm}$ thick CCL). It is critical to address such gradient by mitigation thereof through ensuring at least direct/intimate contact and normal loading for composite liners, or by alternative means. Although direct contact between geomembrane and $\mathrm{GCL}$ or $\mathrm{CCL}$ is pursued by particular construction techniques and ballast layers to overcome wrinkling etc., the low interface transmissivity affecting barrier performance is achieved only when loading exceeds about $50 \mathrm{kPa}$.

Although it is normal practice to have a double composite liner separated by a LDS for Type 1 waste, containment alternative designs of same performance can be achieved without the use of a GCL or clay component to the primary composite liner when the nature of waste and loading requires so. This is achieved, typically for acids and concentrated brine liquid waste, by what is commonly referred to as the triple geomembrane liner (Figure 11) (Shukla 2012) which alternative design was pioneered in South Africa in the 1990s as a cost-effective alternative in the mining industry, and later adopted for water treatment works (reverse osmosis plants) associated therewith.

In respect of salts, the triple geomembrane type of alternative as used for brine waste was noted in which the Class A barrier primary composite liner, of geomembrane plus CCL or GCL, is replaced by two geomembranes separated by a drainage layer. In this case, the upper two geomembranes with separating drainage layer serve as equivalent to unit hydraulic gradient above the LDS and secondary composite liner.

There is often no ballast layer above the primary liner. Such ballast layer would normally protect the geomembrane from UV light and heat which accelerate degradation, as well as protect the liner from wind and/or mechanical damage. It is inconsistent to have a concrete access ramp for vehicles and then allow traffic of vehicles over the unprotected geomembrane liner.

Although the upper two geomembranes separated by a drainage layer are accepted as serving equivalent performance to a Class A primary composite liner, the then LDS is above the secondary composite liner, which in a proposed design is often also just a single geomembrane. Furthermore, the lower liner being on a bed of sand or geotextile renders its composite effect as null and void. This lower geomembrane/geomembrane interface should be drained and preferably under gravity from the lowest point to a monitoring sump at which the performance of the overlying system is measured. It should be noted that a drainage layer is given effect by the presence of a low permeability layer beneath it.

The question of thermal conductivity across barrier systems has been studied by various persons over the past decade or so. Early work in the DWS laboratory in Pretoria West showed thermal gradients across double geocomposite liners to be about $2^{\circ} \mathrm{C}$ irrespective of the temperature, but note this primary liner had a moist $\mathrm{GCL}$ in contact with the overlying geomembrane. This research development was published at Landfill Interest Group (LIG) Durban 2005 and Sardinia 2007 (Legge et al. 2007), but detracts from the particular brine lagoons or PCDs design of a primary geomembrane liner only and secondary liner, or 
double geocomposite barrier, both with a protection layer for traffic during salt recovery in the evaporation dams.

When two liners are separated by an air void induced by a spacer of geonet, or cuspated drain, or geotextile, or similar material, the air void acts as a thermal barrier (see Singh \& Bouazza 2013 for thermal conductivity of HDPE geomembranes, wet and dry GCLs, and wet and dry geotextiles.) As the primary geomembrane heats up due to say solar radiation in exposed conditions, so the enclosed air void reaches the same temperature and heats the drainage layer and secondary liner. The extent to which the drainage layer and in particular the usually thinner secondary geomembrane liner cools is largely dependent on the moisture content and conductivity of what lies beneath it. If it is a moist/wet GCL or soil, then the heat in the secondary liner can be conducted away from the liner as quick as it passes through that geomembrane. The same can be said for designs with geotextiles beneath the secondary liner; however, the elevated temperature tends to drive off moisture from GCLs (Rowe 2018), and obviously the same drying applies to geotextiles as well. If the air void remains trapped, such as in double glazed windows of northern Europe, then the temperature of the upper liner and barrier system rises even higher than the norm due to the lower thermal conductivity of underlying layers inhibiting heat escape (see paper on wrinkles by Take et al. $2014,2015)$. The temperature difference of geomembranes at wrinkles is typically $10^{\circ} \mathrm{C}$ higher than adjacent area to the wrinkle where the membrane is in direct contact with soil or hydrated GCL.

In the case of double geomembrane only liners, the primary liner could be cooled by overlying liquid, but more importantly is to avoid the air temperature in the spacer voids from rising excessively. By moving the air or ventilation, the separating structure does not increase in temperature to the same extent. Even a $10^{\circ} \mathrm{C}$ drop in liner temperature will substantially increase the service life (Rowe 2005, 2012). Alternatively, the liner could be covered with say a soil cement layer, or high performance geomembrane specifically developed for such conditions could be used to partly mitigate this exposure impact. The nature and extent of cover layers in lieu of ballast bags would be influence by amongst others the shape of the floor area and nature of the sediment or precipitate to be removed.

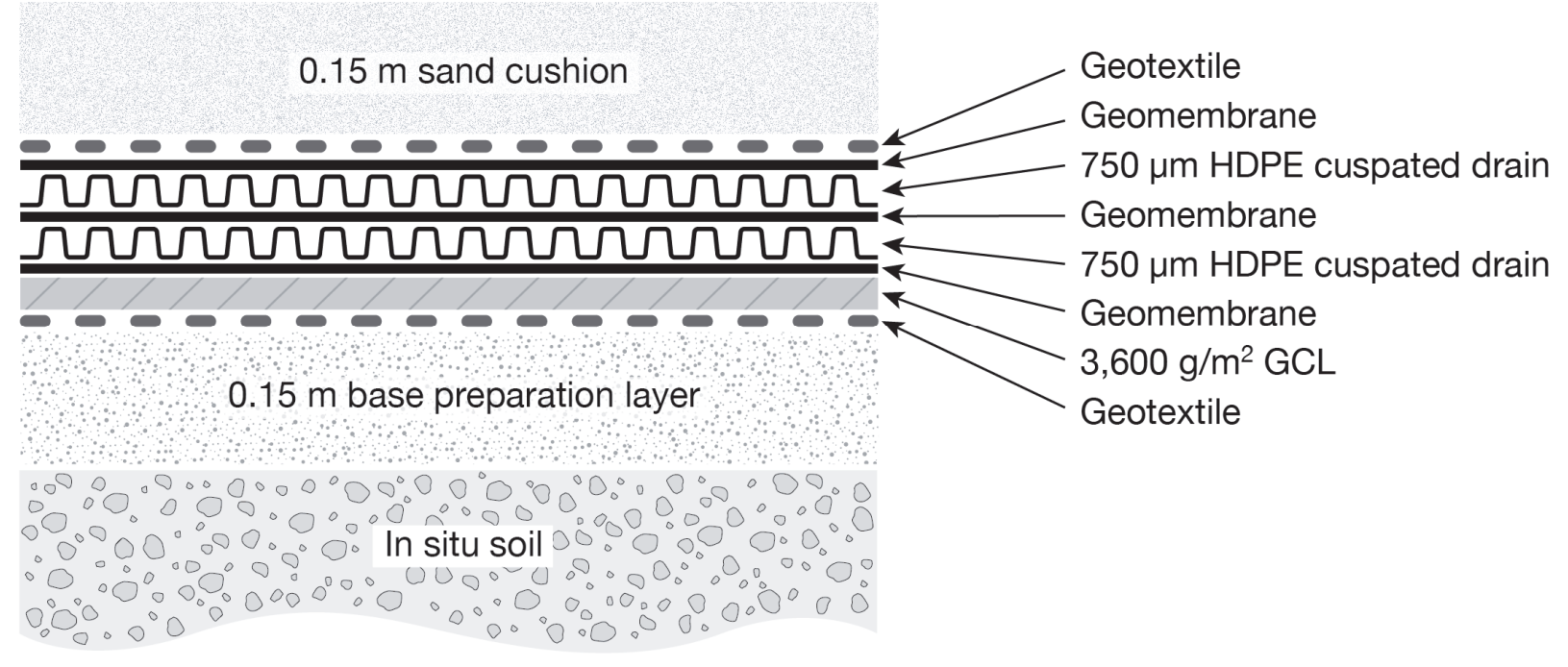

Figure 11 Brine evaporation dam barrier system type drawing (after Shukla 2012)

\subsection{Wastes containing volatile organic compounds}

The performance of composite liners with respect to total solute transport is widely published (Foose et al. 2001). Similarly, it is widely known that the rate of diffusion of volatile organic compounds (VOC) even through perfectly intact liner systems is influenced by temperature (Rowe et al. 2004), and the partitioning coefficient of the compounds being considered.

To mitigate this diffusive characteristic, designers may consider alternative materials, alternative systems or combinations thereof to either contain the VOC stream to a greater extent, or to remove the diffused 
VOCs from further diffusion potential and treatment (Legge et al. 2007). Interested persons are referred to methods of treatment of VOCs such as at Casey Station in Antarctica (Rowe \& Ewais 2014) and at a petrochemical facility containing sludge (Meyer et al. 2014).

\subsection{Sludge lagoons}

Sludge lagoons can be necessary for any type of waste be it assessed as a Type 1, 2, 3 or 4. Geosynthetic materials are prescribed, and even in Type 4, waste facilities maybe elected for use. In the latter case, this could be for water conservation and as is desirable by facility owners as contributing to accelerated drainage and associated reduction in capital costs. In all cases it is critical to understand not only the waste assessment from a chemical perspective, but also its geotechnical parameters, and behaviour upon oxygenation or exposure to air, and when subject to additional normal load which may induce liquefaction of the lower lying material.

The use of drainage layers under low transmissive hydraulic gradients may fail if the particular waste stream results in a precipitate upon drying out. In such cases the drainage layer cannot be kept at atmospheric pressure but needs to be maintained submerged, and the result thereof is that the containment liner design needs to recognise the higher hydraulic gradient. Irrespective of whether a precipitate may form or not, the filter compatibility between waste stream and filter material needs to be taken into consideration for such ultra-fine non-cohesive materials, and augmented by physical testing (Sherard \& Dunnigan 1989). By employing negative pressures to the pore water pressure within a sludge, the rate of drainage can be accelerated by an order of magnitude.

In the design of such lagoons, the question of means of drainage becomes debatable: should gravity systems be applied or suction systems? In the event of blanket filter drains having been omitted historically, consideration may be given to the use of prefabricated vertical drains for particular applications (GRI Report 46, Koerner 2017); however, caution should be exercised with respect to limiting vertical stress and depth of installation so as to avoid rupture or damage to baseliners. The designer should also take into consideration the effect of a loss in integrity of the liner system on the supporting embankment, as that structure is essentially acting as a dry dam or levee. Designers are referred to the ICOLD Bulletin 164 (ICOLD 2017) on suffusion, and current work of the United States Society on Dams (USSD) on such embankments which are susceptible to drying and desiccation cracking, in which case competent filter protection may be critical to safety of the embankment.

\section{$9 \quad$ Conclusions and recommendations}

\section{$9.1 \quad$ Conclusion 1}

Available water is limited and in many regions the assimilative capacity of the remaining water resources to remediate effects of pollutants has been exceeded. In the near future, users of water such as mining developments may be found wanting and today's decisions addressing water conservation and treatment along with embracing ecosystem services will provide for mining activities beyond the next decade.

\subsection{Conclusion 2}

The change in philosophy and amendment to regulation pertaining to water resources protection has been necessary in recognition of this scarce renewable resource and the consequences of past activities. The claim that the geomembrane element of containment barrier systems required for water resource protection is unaffordable does not take into consideration the cost of augmenting present or developing additional water supply, nor the socio-economic costs associated with abandonment of current pollution control standards.

Competent barrier systems incorporating drainage and composite liners have containment performance many orders of magnitude better than the past practice of relying on attenuation or merely monitoring for 
the presence of leachate in water deficit areas. For medium and large waste sites there is a cost equivalence between past and present prescriptive barriers, however the pollution prevention performance is improved as much as a million times.

\subsection{Conclusion 3}

The means of contaminant containment by barriers follows a systems approach. The mechanism of pollution control barrier performance and interaction with the specific waste or pollutant body needs to be comprehensively understood in order to achieve a competent compliant facility through the design, construction and operation phases. This includes the need to understand not only the waste or pollutant risk and resultant assessment as a particular type, but also requires understanding of the waste stoichiometry and physical attributes, as well as how they change with time with resultant effect on contaminant, containment drains and liners over the service life of the facility.

A sound design alone does not provide assurance of pollution prevention due to potential detrimental influences during construction or operation. In the same manner that a design is to be certified by a competent person, so to should the construction be undertaken by a competent person and similarly operated by a competent person. While this may be addressed in part in CQA programmes by specifying standards or certification, the risk of substandard performance increases with phased construction and changes in personnel, roles and responsibilities.

\subsection{Conclusion 4}

The norms and standards prescribe a barrier system layout with implied performance along with a suite of technical considerations which allow for alternative layouts and materials provided the alternative system maintains equivalent performance. The use of alternative materials, be they geosynthetic or other materials, or use of the waste itself in part, as fulfilment of functions requires a definitive assessment rather than a descriptive assessment. The design and its evaluation is based on specified performance criteria and materials evaluated to confirm their suitability. The failure to base design on established parameters can lead to significant cost increases and even failures during construction and/or operation. The specification of a sound geosynthetic product within a design does not imply a sound design nor acceptable performance of the barrier system. It is recommended that the design process establishes the sensitivity of the design to different values for parameters used in quantification of performance. In mining waste deposition, the opportunity exists to make use of the tailings material itself to contribute to water conservation and pollution control performance of barrier systems, with simultaneous reduction in materials and development costs.

\subsection{Conclusion 5}

Many waste management facility owners are uninformed about technologies and thus put their trust exclusively into a single contracted professional service provider, which has on occasion resulted in substandard and unsafe facilities or excessive infrastructure costs. There is significant value to be gained in the appointment of an independent reviewer who reports directly to the owner with the express purpose of exploring the design and construction process, for both compliance with regulatory norms and standards and simultaneous cost efficiencies.

Professional service providers do not always put the client's profitability first. This can be due to various factors including maximising unnecessary study components; erroneous waste assessment; the implied development of unnecessary infrastructure including excessive barrier systems; and/or specification of specific brand products in lieu of performance based specifications or allowing of alternatives of equivalent performance. 


\subsection{Conclusion 6}

Tender documentation should include declarations of interest and exclude bids with anti-competitive or corrupt activities.

\subsection{Conclusion 7}

The failure to include instrumentation in the design and construction of waste facilities to monitor performance during the operational life can result in losses to owners through regulatory actions and community complaints that lead to post facto expensive investigations, temporary or permanent closures of facilities, and loss of valuable airspace.

\section{$9.8 \quad$ Conclusion 8}

If there is not a clear distance between designers and regulators the value of the regulatory role is diminished or even corrupted. Owners and applicants should accompany their professional service providers at presentations as a measure of control over both the regulator and the applicant's professional service providers.

\subsection{Conclusion 9}

Both, the economic viability of a mining development and the ecosystem services use within a regional context have limitations beyond which either the economy or ecosystem or both may collapse. However, the cooperation between all parties affecting the ecosystem within which the development functions and the economy of the activity, within the individual and joint responsibilities of the parties will lead to sustained mining or industrial activities and growth in the sector with associated socio-economic benefits.

\section{Acknowledgement}

The author thanks the Director General of the Department of Water and Sanitation for permission to publish this paper and for the privilege of serving the public through employment in the department.

Portions of this paper were originally published in 'Lessons learnt from 1000 design reviews: raw truths and blatant lies' as it appeared in the Proceedings of the LANDFILL 2017 Seminar "Back to Basics" published by the KwaZulu-Natal Landfill \& Waste Treatment Interest Group.

\section{References}

Acikel, AS, Gates, WP, Singh, RM, Bouazza, A \& Rowe, RK, 2018, 'Insufficient initial hydration of GCLs from some subgrades: factors and causes', Geotextiles and Geomembranes, vol. 46(2018), pp. 770-781.

Alphabet Inc. 2019, Google Earth image, https://bitly.com/

Basson, MS, Combrinck, A, Schroder, JH \& Rossouw, JD 2010, Assessment of the Ultimate Potential and Future Marginal Cost of Water Resources in South Africa, DWA Report no. P RSA 000/00/12610, Department Water Affairs, Republic of South Africa, PSP Report no. J01330-12, September 2010, 178 p.

Ball, JM 2002, 'Milestones towards minimum requirements', Proceedings of the International Waste Management Biennial Congress \& Exhibition, Institute of Waste Management of Southern Africa, Roodepoort.

BAM 2015, Guidelines for the Certification of Protection Layers for Geomembranes in Landfill Sealing Systems, 5th edn, issued by Division 4.3 'Contaminant Transfer and Environmental Technologies'.

Beck, A 2015, 'Available technologies to approach zero leaks', Proceedings of the Geosynthetics 2015 Conference, Industrial Fabrics Association International, Roseville.

Benson, CH 2017, 'Characteristics of gas and leachate at an elevated temperature landfill', Proceedings of GeoFrontiers 2017, pp. 313-322.

Brink, D, Shamrock, J, Nortje, R, Johns, J \& Msiza, J 2009, 'Some pitfalls in the design of lining and capping systems for landfills', Landfill Interest Group Conference, Western Cape, South Africa.

Cedergren, HR 1968, Seepage, Drainage, and Flow Nets, 3rd edn, Wiley-Interscience Publications, Hoboken.

Chen, J, Benson, CH, Likos, WJ \& Edil, TB 2017, 'Interface shear strength of a bentonite-polymer geosynthetic clay liner and a textured geomembrane', Proceedings GeoFrontiers, pp. 219-226.

Chou, YC, Rowe, RK \& Brachman, WI 2018, 'Erosion of silty sand tailings through a geomembrane defect under filter incompatible conditions', Canadian Geotechnical Journal, November, vol. 55, pp. 1564-1575. 
Constitutional Court of South Africa 2015, Case CCT 216/14: Shoprite Checkers (Pty) Limited v Member of the Executive Council for Economic Development, Environmental Affairs and Tourism: Eastern Cape and Others [2015], ZACC 23, 30 June 2015, South Africa.

Department of Water Affairs and Forestry (DWAF) 1998, Minimum Requirements for Waste Disposal by Landfill, 2nd edn, Waste Management Series, ISBN 0620-22993-4.

Department of Water Affairs (DWA) 2009, Welbedacht Report, Welbedacht Dam Capacity Determination, Report number D200-01 By Directorate: Spatial and Land Management.

Department of Water Affairs (DWA) 2010, Integrated Water Resource Planning for South Africa, A Synopsis of the Situation for Key Systems, October 2010.

Dolez, P, Beaumier, D, Taghizadeh, A \& Blond, E 2017, 'Effect of white and black colors on heat generation in polyethylene geomembranes exposed to solar radiation', Proceedings of GeoFrontiers 2017, pp. 259-266.

Dolez, P \& Blond, E 2017, 'Evaluation of geotextile performance for the filtration of fine-grained tailings', Proceedings of GeoFrontiers 2017, pp. 269-277.

Doll, P 1997, 'Desiccation of mineral liners below landfills with heat generation', Journal of Geotechnical and Geoenvironmental Engineering, November 1997.

Dzikiti, S, Schachtschneider, K, Naiken, V, Gush, M, Moses, G \& Le Maitre, DC 2013, 'Water relations and the effects of clearing invasive Prosopis trees on groundwater in an arid environment in the Northern Cape, South Africa', Journal of Arid Environments, vol. 90, pp. 103-113.

Eldesouky, HMG \& Brachman, RWI 2018, 'Calculating local geomembrane strains 724 from a single gravel particle with thin plate theory', Geotextiles and Geomembranes, 725 vol. 46, no. 1, pp. 101-110.

Elges, HFWK 1985, 'Problem soils in South Africa - state of the art, The Civil Engineer in South Africa, vol. 27, issue 7, pp. 341-345.

Engineering Council of South Africa 2017, Code of Conduct for Registered Persons: Engineering Profession Act 2000 (Act No. 46 of 2000), Board Notice 41, Government Gazette, No. 40691, pp. 142-147.

Ewais, AMR, Rowe, RK \& Scheirs, J 2014, 'Degradation of 2.4mm HDPE geomembrane with high residual HP-OIT', Proceedings of the 10th International Conference on Geosynthetics, International Geosynthetics Society, Jupiter.

Foose, GJ, Benson, CH \& Edil, TB 2001, 'Analytical equations for predicting concentration and mass flux from composite liners', Geosynthetics International, vol. 8, no. 6, pp. 551-575.

Fourie, F, Khumbalani, M, Verster, H \& van Dyk, G, 2002, 'The effect of vegetation (Prosopis Sp.) on groundwater levels in Rugseer River, Kenhardt, South Africa', technical report, Department of Water Affairs South Africa.

Froneman, J, Moseneke, DCJ \& Madlanga, J 2015, Shoprite Checkers (Pty) Limited v Member of the Executive Council for Economic Development, Environmental Affairs and Tourism, Eastern Cape and Others (CCT 216/14) [2015] ZACC 23; 2015 (6) SA 125 (CC, 2015 (9) BCLR 1052 (CC) (30 June 2015).

GIGSA Newsletter 1999, 'Fairness associated with specifications', November 1999.

Giroud, JP, Badu-Tweneboah, K \& Soderman, KL 1994, 'Evaluation of landfill liners', Proceedings of the Fifth International Conference on Geotextiles, Geomembranes and Related Products, International Geotextile Society, Singapore, vol. 3, pp. 981-986.

Hao, Z, Sun, M, Ducoste, J \& Barlaz, M 2017, 'A model to describe heat generation and accumulation at municipal solid waste landfills', Proceedings of GeoFrontiers 2017, pp. 281-288.

Hornsey, WP 2013, 'Performance of cushion geotextiles for liner protection applications', presentation at GeoAfrica 2013 Conference, Ghana.

ICOLD 1986, 'Geotextiles as filters and transitions in fill dams', ICOLD Bulletin 55, CIGB Publications.

ICOLD 1994a, 'Embankment dams granular filters and drains: review and recommendations', Bulletin 95, CIGB Publications.

ICOLD 1994b, 'Tailings dams design of drainage: review and recommendations', Bulletin 97, CIGB Publications.

ICOLD 1995, 'Dam failures statistical analysis', Bulletin 99, CIGB Publications.

ICOLD 2013, 'Historical review on ancient dams', Bulletin 143, CIGB Publications.

ICOLD 2017, 'Internal erosion of existing dams, levees and dikes and their foundations', Bulletin 164, CIGB Publications.

Juta, H 1907, Water Rights Under the Common Law and the Irrigation Act No. 32 of 1906, viewed 25 March 2019, https://catalog.hathitrust.org/Record/100475514

Khilnani, K, Stark, TD \& Bahadori, TM 2017, 'Comparison of single and multi-layer interface strengths for geosynthetic/geosynthetic and soil/geosynthetic interfaces', Proceedings of GeoFrontiers 2017, pp. 42-51.

Koerner, RM \& Koerner, JM 2007, GRI's Second Worldwide Survey of Solid Waste Landfill Liner and Cover Systems, GRI Report No. 34 .

Koerner, GR \& Koerner, RM 2017, 'The durability of exposed geomembrane covers', Proceedings of GeoFrontiers 2017, pp. 139-145.

Koerner, RM \& Wong, W 2011, Analysis and Critique of Twenty Large Solid Waste Landfill Failures, GRI Report No. 41, 17th October 2011.

Koerner, RM 2017, Utilizing PVDs to Provide Shear Strength to Saturated Fine-Grained Foundation Soils, GRI Report 46, 28 July 2017.

Legge, KR 1990, 'A new approach to geotextile selection', Proceedings of the 4th International Conference on Geotextiles Geomembranes and Related Products, vol. 3, A.A. Balkema, pp. 1040-1041.

Legge, KR, Legg, PA \& Meyer, PJ 2007, 'Coupled solution to heat induced degradation of containment barriers', Proceedings of the 11th International Waste Management and Landfill Symposium, Environmental Sanitary Engineering Centre, Cagliari.

Legge, KR, Fricker, C, Mnisi, K, Nemusibi, K \& Seake, B 2014, 'Service life considerations of pollution control barrier systems', SAICE Civil Engineering Magazine, vol. 22, no. 7. 
Legge, KR, Fricker, C \& Mnisi, K 2015, 'Pollution prevention awareness for municipal managers in South Africa, SAICE Civil Engineering Magazine, vol. 23, no. 9.

Le Maitre, DC, Forsyth, G, Dzikiti, S \& Gush, MB 2016, 'Estimates of the impacts of invasive alien plants on water flows in South Africa', Water SA, vol. 42, no. 4.

Liefferink, M, 2012, Environmental Risks and Hazards Pertaining to AMD and Radioactivity within the Witwatersrand Goldfields, Powerpoint presentation made to the Endangered Wildlife Trust, Johannesburg Country Club.

Lu, Y, Abuel-Naga, H, Leong, EC, Bouazza, A \& Lock, P 2018, 'Effect of water salinity on the water retention curve of geosynthetic clay liners', Geotextiles and Geomembranes, vol. 46, pp. 707-714.

Mallory, SJL, Versveld, D \& Nditwani, T 2011, 'Estimating stream-flow reduction due to invasive alien plants: are we getting it right?', South African National Committee for the International Association of Hydrological Sciences (SANCIAHS) Symposium.

McWatters, R, Rowe, KR \& Jones, D 2015, 'Co-extruded geomembranes in barrier systems in extreme environments - from high temperature laboratory tests to Antarctica field sites', Proceedings of the Geosynthetics 2015 Conference, Industrial Fabrics Association International, Roseville.

Msadala, VP \& Basson, GR 2009, Sediment Yield Prediction Based on Analytical Methods and Mathematical Modelling, thesis (in partial fulfilment of a degree of Master of Science), University of Stellenbosch, Stellenbosch.

Meyer, W, Meyer, PJ \& Gundle, C 2014, 'Expanding containment barrier boundaries', Proceedings of the 10th International Conference on Geosynthetics, International Geosynthetics Society, Jupiter.

Morgenstern, NR, Vick, SG \& Van Zyl, D 2015, Report on Mount Polley Tailings Storage Facility Breach, Independent Expert Engineering Investigation and Review Panel, British Columbia, 30 January 2015, unpublished.

Morsy, MS \& Rowe, RK 2017, 'Performance of blended polyolefin geomembrane in various incubation media based on Std-OIT', Proceedings of GeoFrontiers 2017, pp. 1-10.

National Treasury of South Africa 1999, Public Finance Management Act No. 1 of 1999, viewed 25 March 2019 , http://www.treasury.gov.za/legislation/PFMA/act.pdf

National Treasury of South Africa 2004, Supply Chain Management: A Guide for Accounting Officers/Authorities, viewed 28 March 2019, https://www.environment.gov.za/sites/default/files/legislations/accountingofficer_scmguide.pdf

Palm, JG \& Visser, JL 2015, 'Landfill licensing and liners', Western Cape LIG Seminar, Tulbagh, 15-16 September 2015.

Pavanello, P, Carrubba, P \& Moraci, N 2018, 'Dynamic friction and the seismic performance of geosynthetic interfaces', Geotextiles and Geomembranes, vol. 46(2018), pp. 715-725.

Peggs, ID, Schmucker, B \& Carey, P 2005, 'Assessment of maximum allowable strains in polypropylene geomembranes', Proceedings Geofrontiers 2005, Austin Texas.

Preston, IR, Le Maitre, DC, Blignaut, JN, Louw, L \& Palmer, CG 2018, 'Impact of invasive alien plants on water provision in selected catchments', Water SA, vol. 44, no. 4, pp. 719-729.

Reinhart, DR, Mackay, R, Levin, S, Joslyn, R \& Motlagh, A 2017, 'Field investigation of an elevated temperature Florida landfill', Proceedings of GeoFrontiers, pp. 298-301.

Republic of South Africa 1979, White Paper K-79: Supplementary Report on the Proposed Vaal Dam Betterments and Additional Storage, Republic of South Africa.

Republic of South Africa 1982, White Paper C-82: Second Supplementary Report on the Proposed Vaal Dam Betterments and Additional Storage, Republic of South Africa.

Republic of South Africa 1998a, 'Competition Act No. 89 of 1998', Government Gazette, vol. 400, no. 19412, 36 p.

Republic of South Africa 1998b, 'National Water Act No. 36', Government Gazette, vol. 398, no. 19182, pp. 1-152.

Republic of South Africa 1998c, 'National Environmental Management Act 107 of 1998', Government Gazette, no. 19519.

Republic of South Africa 2000, 'Engineering Professions Act No. 46', Government Gazette, vol. 426, no. 1821, 20 p.

Republic of South Africa 2008, 'National Environmental Management: Waste Act, 2008 (Act No. 59 of 2008)', Government Gazette, no. 36784.

Rowe, RK, Quigley, RM, Brachman, RWI \& Booker, JR 2004, Barrier Systems for Waste Disposal Facilities, 2nd edn, E \& FN Spon, Milton Park.

Rowe, RK \& Van Gulck, JF 2004, 'Filtering and drainage of contaminated water', in AB Fourie (ed.), Proceedings of the Fourth International Conference on Geofilters, University of the Witwatersrand, Johannesburg, pp. 1-63.

Rowe, RK 2005, 'Long term performance of containment barrier systems', Géotechnique, vol. 55, no. 9, pp. 631-678.

Rowe, RK 2011, Geosynthetics in Bottom Liners and Covers for Use in Lagoons, Secondary Containment, Landfill and Mining Applications, GIGSA Seminar, Stone Cradle, Gauteng, South Africa, 6th-7th September 2011.

Rowe, RK 2012, 'Short and long-term leakage through composite liners. The 7th Arthur Casagrande Lecture', Canadian Geotechnical Journal, vol. 49, no. 2, pp. 141-169.

Rowe, RK \& Ewais, AMR 2014, 'Degradation behaviour of HDPE geomembrane with high and low initial high-pressure oxidative induction time', Geotextile and Geomembranes, vol. 42, iss. 2, April, pp. 111-126.

Rowe, RK, Joshi, P, Brachmann, RWI \& McCleod, H 2017, 'Leakage through holes in geomembranes below saturated tailings', Journal of Geotechnical and Geoenvironmental Engineering, vol. 143, iss. 2, 2017.

Rowe, RK 2018, 'Geosynthetic clay liners: perceptions and misconceptions', Proceedings of the 11th International Conference on Geosynthetics, Korean Geosynthetics Society, Seoul.

Rowe, RK \& Yu, Y 2019, 'Magnitude and significance of tensile strains in geomembrane landfill liners', Geotextiles and Geomembranes, https:dx.doi.org/10.1016/j.geotexmem.2019.01.001

Sample-Lord, KM, Bohnhoff, GL \& Tong, S 2017, 'Diffusion of calcium chloride through polymerized bentonite', Proceedings of GeoFrontiers 2017, pp. 200-208. 
Scalia, J \& Benson, CH 2011, 'Hydraulic conductivity of geosynthetic clay liners exhumed from landfill final covers with composite barriers', ASCE Journal of Geotechnical and Geoenvironmental Engineering, January 2011, vol. 1, pp. 1-13.

Scott, DF, Le Maitre, DC \& Fairbanks, DHK 1998, 'Forestry and streamflow reductions in South Africa: a reference system for assessing extent and distribution', Water SA, vol. 24, no. 3, July.

Shamrock, J \& Msiza, J 2015, 'HDPE geomembrane specification and performance implications', Western Cape LIG Seminar, Tulbagh, 15-16 September 2015.

Sherard, JL \& Dunnigan, LP 1989, 'Critical filters for impervious soils', Journal of Geotechnical Engineering, vol. 115, no. 7, July 1989, ASCE, ISSN 0733-9410/89/0007-0927

Shukla, SK 2012, Handbook of Geosynthetic Engineering, 2nd edn, ICE Publishing, London, p. 289.

Singh, M, Kijko, A \& van den Berg, L 2010, 'Seismic risk ranking for large dams in South Africa', Acta Geophysica, Institute of Geophysics, Polish Academy of Sciences.

Singh, RM \& Bouazza, A 2013, 'Thermal conductivity of geosynthetics', Geotextiles and Geomembranes, vol. 39(2013), pp. 1-8.

Stark, TD \& Jafari, NH 2017, 'Landfill operational techniques in the presence of elevated temperatures', Proceedings of GeoFrontiers 2017, pp. 289-297.

Take, A, Brachman, WI, Rowe, RK \& Rentz, A 2014, 'Temperature measurements of exposed GMB/GCL composite liners', Proceedings of the 10th International Conference on Geosynthetics, Deutsche Gesellschaft fuer Geotechnik, Essen.

Take, WA, Brachman, RWI \& Rowe, RK 2015, 'Observations of bentonite erosion from solar-driven moisture migration in GCLs covered only by a black geomembrane', Geosynthetics International, vol. 22, iss. 1, pp. 78-92.

Tian, K, Benson, CH \& Likos, WJ 2017, 'Effect of anion ratio on the hydraulic conductivity of a bentonite-polymer geosynthetic clay liner', Proceedings of GeoFrontiers 2017, pp. 180-189.

Tognon, AR, Rowe, RK \& Moore, ID 2000, 'Geomembrane strain observed in large scale testing of protection layers', Journal of Geotechnical and Geoenvironmental Engineering, vol. 126, no. 12, pp. 1194-1208.

Union of South Africa 1934, Vaal River Development Act, Act 38 of 1934.

Union of South Africa 1940, Irrigation and conservation of waters act, 1912 (act no. 8 of 1912) with amendments to March, 1940: Besproeiing- en waterbewaringswet, 1912 (wet no. 8 van 1912) met amendemente tot Maart 1940 / Unie van Suid-Afrika, Government Printer, Pretoria.

Union of South Africa 1956, Water Act, No. 54 of 1956, Statutes of the Republic of South Africa - Water, pp. 1201-1399, viewed 25 March 2019, http://goo.gl/PzIISQ

van Rooyen, JA \& Versfeld, DB 2010, Integrated Water Resource Planning for South Africa: A Situation Analysis 2010, Department of Water Affairs, Pretoria, viewed 28 March 2019, http://www.dwa.gov.za/Documents/Other/Water\%20Resources/ IntegratedWRPlanningSA-2010.PDF

Weng, J 2017, 'Feasibility of vacuum consolidated with stereo drain system in surface pre-reinforcement of dredged spoil', Korean Society of Civil Engineers, Journal of Civil Engineering, published online August 31, 2017, pp. 1-6.

World Resources Institute 2003, Watersheds of the World: Global Maps, 15. Annual Renewable Water Supply Per Person by Basin for 1995 and Projections for 2025, viewed 28 March 2019, http://pdf.wri.org/watersheds_2003/gm15.pdf

World Resources Institute 2015, Extreme Water Shortages are Expected to Hit These Countries by 2040, article by Jeff Desjardins, August 31, 2015, www.visualcapitalist.com

\section{Bibliography}

Abdelaal, FB \& Rowe, RK 2015, 'Durability of three HDPE geomembranes immersed in different fluids at $85^{\circ} \mathrm{C}^{\prime}$, Journal of Geotechnical and Geoenvironmental Engineering, vol. 141, iss. 2.

Ali, MA \& Bouazza, A, Singh, RM, Gates, WP \& Rowe, K 2016, 'Thermal conductivity of geosynthetic clay liners', Canadian Geotechnical Journal, vol. 53, no. 9, pp. 1510-1521.

Ashe, LE, Rowe, RK and Brachman, RWI 2015, 'Laboratory study of downslope erosion for 10 different GCLs', Journal of Geotechnical and Geoenvironmental Engineering, vol. 141, no. 1.

Benson, CH, Jo, HY \& Musso, T 2015, 'Hydraulic conductivity of organoclay and organoclay-sand mixtures to fuels and organic liquids', Journal of Geotechnical Engineering, vol. 141, no 2.

Benson, CH 2016, Exothermic Reactions in Elevated Temperature Landfills: Field Observations and Laboratory Experiments, webinar, https://event.on24.com/eventRegistration/EventLobbyServlet?target=registration.jsp\&eventid=1289154\&sessionid=1\&key $=923971055 B 5 D F A 903 F 65 E B 8 B 518 F 3413 \&$ sourcepage=register

Bouazza, MA 2016, 'New insight on geosynthetic clay liner hydration: the key role of subsoil mineralogy', Geosynthetics International, vol. 24, no. 2, pp. 139-150.

Charpentier, C 2016, 'Case study on electrical leak location using both water puddle and dipole methods on a mining waste cap totalling $255000 \mathrm{~m}^{2 \prime}$, Proceedings of the 3rd Pan-American Conference on Geosynthetics, International Geosynthetics Society, Jupiter.

Copeland, A 2014, 'Do all TSF's leak and need to be lined?', discussion paper, Proceedings of the 5th International Mining and Industrial Waste Management Conference.

Croft, F 2015, 'Has there been any change in professional conduct?', Civil Engineering, March.

Dashko, R \& Shidlovskaya, A 2016, 'Impact of microbial activity on soil properties', Canadian Geotechnical Journal, May.

Davies, P \& Legge, KR 2003, 'Geosynthetic clay liners: use and abuse in South Africa', Ninth International Waste Management and Landfill Symposium, Sardinia. 
Department of Water Affairs and Forestry (DWAF) 2002, Guidelines on Provision to be made for the Impacts of Sedimentation in the Positioning of Purchase Lines around Reservoir Basins, A Rooseboom, SIGMA BETA, Consulting Civil Engineers.

Department of Water Affairs (DWA) 2010, Assessment of the ultimate potential and future marginal cost of water in South Africa, Report No. P RSA 000/00/12610 and PSP No. J01330-12, September 2010.

Dickson, S, Brachman, RWI \& Rowe, RK 2010, 'Thickness and hydraulic performance of geosynthetic clay liners overlying a geonet', Journal of Geotechnical and Geoenvironmental Engineering, April.

Edil, T 2007, 'Is aqueous-phase VOC transport from modern landfills a potential environmental problem', Proceedings 11th International Waste Management and Landfill Symposium, 1-5 October 2007, Sardinia.

Ewais, AMR, Rowe, RK, Brachman, RWI \& Arnepalli, DN 2016, 'Service life of a high-density polyethylene geomembrane under simulated landfill conditions at $85^{\circ} \mathrm{C}$ ', Journal of Geotechnical and Geoenvironmental Engineering, vol. 140, iss. 11, November.

Fourmont, SB \& Koerner, GR 2017, 'Determining the long-term transmissivity of selected drainage geocomposites to landfill leachate', GeoFrontiers Proceedings, pp. 274-280.

Fox, PJ \& Stark, TD 2015, 'State of the art report: GCL shear strength and its measurement - ten-year update', Geosynthetics International, vol. 22, iss. 1, pp. 3-47.

Gilson-Beck, A 2016, 'Best practices for groundwater protection', GeoAmericas Proceedings 2016, Miami.

Giroud, JP, Houlihan, MF, Bachus, RC \& Qureshi, S 1998, 'Clogging potential of geosynthetic leachate collection layers by fine particles from sand protective layers, Proceedings 6th International Conference on Geosynthetics, vol. 1, pp. $185-190$.

Golder Associates 2011, Technical Memorandum, De-silting of Mapochs Dam - Submission to the Regulator, reference number P1613796.

Government Gazette No. 704 of 1999 - National Water Act, Act 36 of 1998, Regulations on Use of water for Mining and Related Activities aimed at the Protection of Water Resources.

Gundle, CJ, Meyer, PJ, Meyer, W \& Schaffner, M 2013, 'Technology response for mitigating environmental impacts to achieve longterm pollution prevention', GeoAfrica 2013 Conference, Ghana.

Haager, M 2014, 'High temperature resistant geomembrane for hot brine', 10th International Conference on Geosynthetics 2014, Berlin, Germany.

Honningford, L 2016, 'Ensuring competent geomembrane installations', SAICE Civil Engineering Magazine, vol. 24, June 2016, South Africa.

Hoor, A 2012, 'Effect of temperature on the service life of landfill liners and potential temperature control strategies', GeoAmericas 2012 Conference, Lima.

Hsuan, Y, Koerner, RM \& Koerner, GR 2015, 'Rationale and background for the GRI-GM13 specification for HDPE geomembranes', GSI White Paper \#32, Geosynthetic Institute, Folsom.

Jafari, NH, Stark, TD \& Rowe, RK 2014, 'Service life of HDPE geomembranes subjected to elevated temperatures', Journal of Hazardous, Toxic, and Radioactive Waste, vol. 18, no. 1, pp. 16-26.

Jones, DD \& Rowe, RK 2016, 'BTEX migration through various geomembranes and vapor barriers', Journal of Geotechnical and Geoenvironmental Engineering, vol. 142, iss. 10, October 2016.

Kaur, A \& Fanourakis, GC 2016, 'The effect of type, concentration and volume of dispersing agent on the magnitude of the clay content determined by the hydrometer analysis', Journal of the South African Institute of Civil Engineering, vol. 58, no. 4, December 2016.

Klein, R, Baumann, T, Kahapka, E \& Niessner, R 2001, 'Temperature development in a modern municipal solid waste incineration (MSWI) bottom ash landfill with regard to sustainable waste management', Journal of Hazardous Material, vol. 83, no. 3, pp. 265-280.

Koerner, GR \& Najero, D 2005, 'Direct shear database of geosynthetic-to-geosynthetic and geosynthetic-to-soil interfaces', GRI Report No. 30, 14 June 2005.

Koerner, RM \& Koerner, GR 2008, 'Inadequate performance of geotextile filters under difficult and challenging field conditions', GRI Report No. 36.

Koerner, RM, Hsuan, Y \& Koerner, GR 2014, 'Exposed lifetime of 19 different geosynthetics in the laboratory and in Phoenix, Arizona', GRI Report No. 44, 16 December 2014.

Legge, KR 2012, 'Composite filters of geotextile and natural materials for critical applications, GeoAmericas 2012 Conference, Lima, Peru.

Lu, N \& Dong, Y 2015, 'Closed-form equation for thermal conductivity of unsaturated soils at room temperature', Journal of Geotechnical and Geoenvironmental Engineering, vol. 141, iss. 6, June 2015.

Mather, A, Netravali, AN \& O' Rourke, TD 1994, 'Chemical aging effects on the physio-mechanical properties of polyester and polypropylene geotextiles', Geotextiles and Geomembranes, vol. 13(1994), pp. 591-626.

Meyer, W \& Meyer, P 2016, 'Construction of the first enhanced barrier system in the world', Civil Engineering, vol. 24, no. 3, April 2016.

Peggs, ID 1985, 'Why quality control? A graphic case history', Geotechnical Fabrics Conference '85, Cincinnati, Ohio.

Qian, X, Gray, D \& Koerner, RM 2004, 'Estimation of maximum liquid head over landfill barriers', Journal of Geotechnical and Geoenvironmental Engineering, ASCE, vol. 130, no. 5, pp. 488-497.

Ramsey, B \& Wu, Y 2013, 'Advances in geomembranes: thermal properties and elevated usage temperatures', GeoAfrica 2013 Conference, Ghana.

Rowe, RK \& Abdelaal, FB 2016, 'Antioxidant depletion in high-density polyethylene (HDPE) geomembrane with hindered amine light stabilizers (HALS) in low pH heap leach environment', Canadian Geotechnical Journal, vol. 53, no. 10, June, pp. 1612-1627. 
Rowe, RK 2016, 'Recent insights regarding the design and construction of modern MSW landfills', EurAsia Waste Management Symposium.

Raviteja, KVNS \& Munwar Basha, B 2015, 'Variability associated with interface friction between geomembrane and soil', 50th Indian Geotechnical Conference, Maharashtra, India.

Shackelford, CD 2014, The ISSMGE Kerry Rowe Lecture: 'The role of diffusion in environmental geotechnics', Canadian Geotechnical Journal, vol. 51, no. 11, pp. 1219-1242.

Southen, JM \& Rowe, RK 2005, 'Thermally induced desiccation of geosynthetic clay liners in landfill basal liner applications', GSP142 Waste Containment and Remediation.

Stott, P \& Theron, E 2016, 'Shortcomings in the estimation of clay fraction by hydrometer', Journal of the South African Institute of Civil Engineering, vol. 58, no. 2, June, pp. 14-24.

Thielmann, SS, Fox, PJ \& Athanassopoulos, C 2016, 'Shear strength of GMX/GCL composite liner under high normal stress', Journal of Geotechnical and Geoenvironmental Engineering, vol. 142, iss. 5, May 2016.

United States Society on Dams (USSD) 2011, Materials for Embankment Dams, ISBN 978-1-884575-49-5, Library of Congress Control Number 2009942447, January 2011, USA.

Vidal, D, Queiroz, PI \& Santos, CT 2014, 'Unsaturated flow behaviour of leak-detection systems with geonets', Proceedings of the 10th International Conference on Geosynthetics, Berlin, Germany.

William, JL 2014, 'Modelling thermal conductivity dryout curves from soil-water characteristic curves', Journal of Geotechnical and Geoenvironmental Engineering, vol. 140, iss. 5, May 2014, USA. 